\title{
Trueness of 12 intraoral scanners in the full-arch implant impression: a comparative in vitro study
}

Francesco Guido Mangano ${ }^{1 *}$ (D) Oleg Admakin ${ }^{1}$, Matteo Bonacina ${ }^{2}$, Henriette Lerner $^{3}$, Vygandas Rutkunas ${ }^{4}$ and Carlo Mangano ${ }^{5}$

\begin{abstract}
Background: The literature has not yet validated the use of intraoral scanners (IOSs) for full-arch (FA) implant impression. Hence, the aim of this in vitro study was to assess and compare the trueness of 12 different IOSs in FA implant impression.

Methods: A stone-cast model of a totally edentulous maxilla with 6 implant analogues and scanbodies (SBs) was scanned with a desktop scanner (Freedom UHD ${ }^{\oplus}$ ) to capture a reference model (RM), and with 12 IOSs (ITERO ELEM

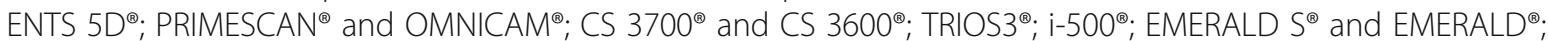
VIRTUO VIVO ${ }^{\circledR}$ and DWIO ${ }^{\oplus}$; RUNEYES QUICKSCAN ${ }^{\circledR}$ ). Ten scans were taken using each IOS, and each was compared to the RM, to evaluate trueness. A mesh/mesh method and a nurbs/nurbs method were used to evaluate the overall trueness of the scans; linear and cross distances between the SBs were used to evaluate the local trueness of the scans. The analysis was performed using reverse engineering software (Studio ${ }^{\circledast}$, Geomagics; Magics ${ }^{\varpi}$, Materialise). A statistical evaluation was performed.

Results: With the mesh/mesh method, the best results were obtained by CS $3700^{\circledR}$ (mean error $30.4 \mu \mathrm{m}$ ) followed

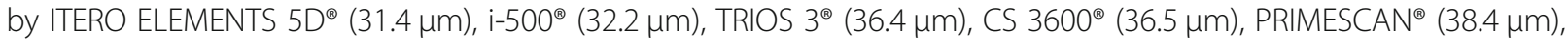
VIRTUO VIVO ${ }^{\circledast}(43.8 \mu \mathrm{m})$, RUNEYES$^{\oplus}(44.4 \mu \mathrm{m})$, EMERALD $^{\circledR}(52.9 \mu \mathrm{m})$, EMERALD $^{\circledR}(76.1 \mu \mathrm{m})$, OMNICAM $^{\circledast}(79.6 \mu \mathrm{m})$ and $\mathrm{DWIO}^{\otimes}(98.4 \mathrm{\mu m})$. With the nurbs/nurbs method, the best results were obtained by ITERO ELEMENTS 5D ${ }^{\circledR}$ (mean

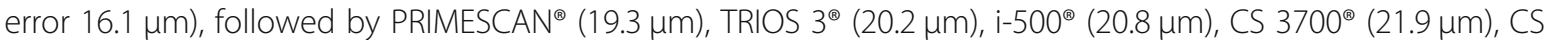

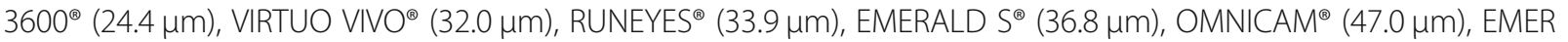
$\operatorname{ALD}^{\oplus}(51.9 \mu \mathrm{m})$ and $\mathrm{DWIO}^{\circledR}(69.9 \mu \mathrm{m})$. Statistically significant differences were found between the IOSs. Linear and cross distances between the SBs (local trueness analysis) confirmed the data that emerged from the overall trueness evaluation.
\end{abstract}

Conclusions: Different levels of trueness were found among the IOSs evaluated in this study. Further studies are needed to confirm these results.

Keywords: Intraoral scanner, Full-arch implant impression, Scanbody, Trueness, Comparative study

\footnotetext{
* Correspondence: francescomangano1@mclink.net

'Department of Prevention and Communal Dentistry, Sechenov First State Medical University, 119992 Moscow, Russia

Full list of author information is available at the end of the article
}

(c) The Author(s). 2020 Open Access This article is licensed under a Creative Commons Attribution 4.0 International License, which permits use, sharing, adaptation, distribution and reproduction in any medium or format, as long as you give appropriate credit to the original author(s) and the source, provide a link to the Creative Commons licence, and indicate if changes were made. The images or other third party material in this article are included in the article's Creative Commons licence, unless indicated otherwise in a credit line to the material. If material is not included in the article's Creative Commons licence and your intended use is not permitted by statutory regulation or exceeds the permitted use, you will need to obtain permission directly from the copyright holder. To view a copy of this licence, visit http://creativecommons.org/licenses/by/4.0/. The Creative Commons Public Domain Dedication waiver (http://creativecommons.org/publicdomain/zero/1.0/) applies to the data made available in this article, unless otherwise stated in a credit line to the data. 


\section{Background}

Intraoral scanners (IOSs) are changing the world of implant prosthodontics $[1,2]$. IOSs use structured light and/or laser to capture sequential images of the patient's dental arches, allowing three-dimensional (3D) reconstruction of their surface using powerful reconstruction software. These software applications generate point clouds that are triangulated to give surface reconstructions (meshes), i.e. virtual models of the patient's dental arches [2,3].

IOS optical impressions allow the dentist to capture virtual models of the patient's dental arches, with no conventional impression using trays and materials (which have always been unwelcome to patients) and without having to pour any plaster cast, saving time and space $[2,4,5]$. The clinical procedure is technically simplified, and the virtual models can be immediately sent to the laboratory as standard tessellation language (STL) files, without disinfection or shipping costs $[2,5,6]$. The optical impressions improve the communication with the dental laboratory, which becomes more efficient, and represents the gateway to the world of computer-aided design and manufacturing (CAD/CAM) [5, 6].

To date, in fixed implant prosthodontics, the scientific literature has validated the use of IOSs for capturing optical impressions for the design and manufacture of shortspan restorations such as single crowns (SCs) [7-10] and partial prostheses (PPs) [11-13]. However, in the case of long-span restorations, and in particular for full arches (FAs), IOSs do not yet seem to be sufficiently accurate, as reported by several studies $[14,15]$ and reviews of the literature $[16,17]$.

In metrics, accuracy is "the closeness of agreement between a measured quantity value and a true quantity value of a measurand" (JCGM 200:2012; ISO 5725-1, 1994) $[2,4,13]$, and when it comes to IOSs, it is the combination of trueness and precision. Trueness is the most important factor, defined as "the closeness of agreement between the arithmetic mean of a large number of test results and the true or accepted reference value". Trueness expresses how much the average of a series of measurements approaches reality; a measurement is truer the closer it is to the actual value of the object. To evaluate the trueness of a measurement requires a reference: in the case of dental models, this is an acquisition made with a machine with certified accuracy (possibly $\leq 5 \mu \mathrm{m}$ ), such as a coordinate measuring machine $(\mathrm{CMM})$, or an industrial optical or desktop scanner $[2,4,13]$. Specifically, the acquisitions obtained with IOSs must be compared with those obtained with one of these reference machines to be mathematically validated. Precision is "the closeness of agreement between measured quantity values obtained by replicate measurements on the same objects under specified conditions": it refers to the closeness of agreement and deviations between test results. To evaluate precision does not require a reference: it is sufficient to compare the measurements made with the same IOS and evaluate the deviations between them $[2,4,14]$.

Because it is not possible to use machines with certified accuracy such as CMMs, articulated arms or industrial scanners in the patient's mouth, and having a certified reference file is not possible, measuring the trueness of optical impressions with IOS in vivo is difficult $[2,4,18]$. Some authors have recently tried to introduce indexes $[19,20]$ or geometric shapes with known dimensions (custom measuring aids) $[21,22]$ in the mouth to evaluate the distortions affecting the optical impression in vivo, but the vast majority of studies of the trueness of IOSs have been made in vitro on plaster models [14, 15, 23-26].

Among these in vitro studies, many have used a mesh/ mesh method, directly superimposing the meshes (virtual models) derived from intraoral scanning with different IOSs onto a reference mesh obtained with a certified industrial or desktop scanner [14, 15, 23, 24]. Although this approach is intuitive and immediate, and provides reliable information about the overall trueness of a scan, it has limitations. First, it uses meshes that are surface reconstructions and therefore geometric approximations of the scanned model, on which it is impossible to perform reliable distance calculations between the different scanbodies (SBs), i.e. the digital transfers of the implant position. In addition, this approach does not really replicate what happens in the early stages of prosthetic CAD modelling. In implant prosthodontics, the first CAD step involves replacing the mesh (which is a surface reconstruction and therefore a geometric approximation) of the SB with the corresponding SB library file, available in the manufacturer's implant library [1, 25-27]. This library file, although saved in the same STL format, is not the result of a 3D acquisition (and therefore a surface reconstruction with geometric approximation, such as a mesh): it is a geometrically perfect file or a non-uniform rational b-spline (nurbs) file, originally designed in CAD, and linked to all the other components of the implant library (bonding bases of different height and diameter) on which the dental technician models the individual abutment or the restoration directly [25-27]. For this reason, investigating the accuracy of an intraoral scan after replacing each of the SBs in the mesh with the corresponding library file, and then superimposing two nurbs files (the position of the SBs in the space obtained with the reference scanner and with the IOSs, respectively), may be important to obtain more reliable information on the overall trueness and to be able to calculate the exact distances between the SBs with 3D calculation software, after having automatically identified 
their centroids. This approach requires substantial work and hundreds of superimpositions but is probably the most suitable to be able to identify the overall and local trueness (distances between the SBs) of an IOS, considering that the distances between the SBs cannot be properly calculated on a mesh [26-28].

The purpose of this in vitro study was therefore to assess and compare the overall trueness of 12 different IOSs, using two different investigation methods (mesh/ mesh and nurbs/nurbs superimposition), and to calculate the exact distances between the different SBs (linear distances between the SBs during the progression of the scan and cross distances, i.e., distances between SBs with different positions in the arch).

\section{Methods}

\section{Study design}

The present in vitro study was designed to assess and compare the trueness of 12 different IOSs (ITERO ELEM ENTS 5D ${ }^{\circ}$, Align Technologies, San José, CA, USA; PRIM ESCAN $^{\circ}$ and $\mathrm{OMNICAM}^{\circ}$, Dentsply Sirona, York, PA, USA; CS $3700^{\circ}$ and CS $3600^{\circ}$, Carestream Dental, Atlanta, GA, USA; TRIOS3 ${ }^{\circ}$, 3-Shape, Copenhagen, Denmark; i$500^{\circ}$, Medit, Seoul, South Korea; EMERALD $S^{\circ}$ and EMER ALD $^{\circ}$, Planmeca, Helsinki, Finland; VIRTUO VIVO ${ }^{\circ}$ and DWIO $^{\circ}$, Dentalwings, Montreal, Canada; RUNEYES QUICKSCAN $^{\circ}$, Runeyes Medical Instruments, Ningbo, Zhejiang, China) in FA implant impression.

This study used a type IV gypsum model representing a totally edentulous maxilla with 6 implant analogues in positions \#11, \#14, \#16, \#21, \#24 and \#26 (right and left central incisors, first premolars and first molars) and high-precision non-reflective polyether-ether-ketone
(PEEK) SBs (Megagen ${ }^{\circ}$ Daegu, South Korea) screwed on (Fig. 1). The SBs were named by convention S1 (\#26), S2 (\#24), S3 (\#21), S4 (\#11), S5 (\#14) and S6 (\#16). The model, which had been also used in a previous study [14], presented pink gum in the areas of the implant analogues and simulated the situation of an implantsupported fixed FA prosthesis.

The gypsum model was first scanned with a powerful desktop scanner (Freedom UHD ${ }^{\circ}$, Dof Inc., Seoul, Korea), to acquire reference virtual models. This desktop scanner uses a white light-emitting diode and has two 5.0 megapixel cameras. It works under patented stable scan stage technology, which allows the cameras and lights to move and rotate above and around the model, which remains stationary. This allows rapid and effective capture of all details of the model in a few steps and in less than $1 \mathrm{~min}$, generating virtual models in STL immediately usable by any CAD. The scanner has dimensions of $330 \times 495 \times 430$ $\mathrm{mm}$ and a weight of $15 \mathrm{~kg}$, is powered at $110-240 \mathrm{~V}$ and $50-60 \mathrm{~Hz}$, and works with Windows operating systems 7, 8, and 10 (64-bit). Three virtual models were captured with this desktop scanner and saved in a dedicated folder, labelled with the scanner name. Then, the quality of these meshes was investigated with reverse engineering software (Studio ${ }^{\circ}$, Geomagics, Morrisville, NC, USA), and always within the same software, the models were cut and trimmed in order to isolate the SBs and to eliminate the pink gingiva area. Once cut and made uniform, these meshes were superimposed for the validation of the superimposition method and for the choice of the reference model (RM) to be used in the study, as previously described [29]. The RM was saved in a specific folder, ready for use.

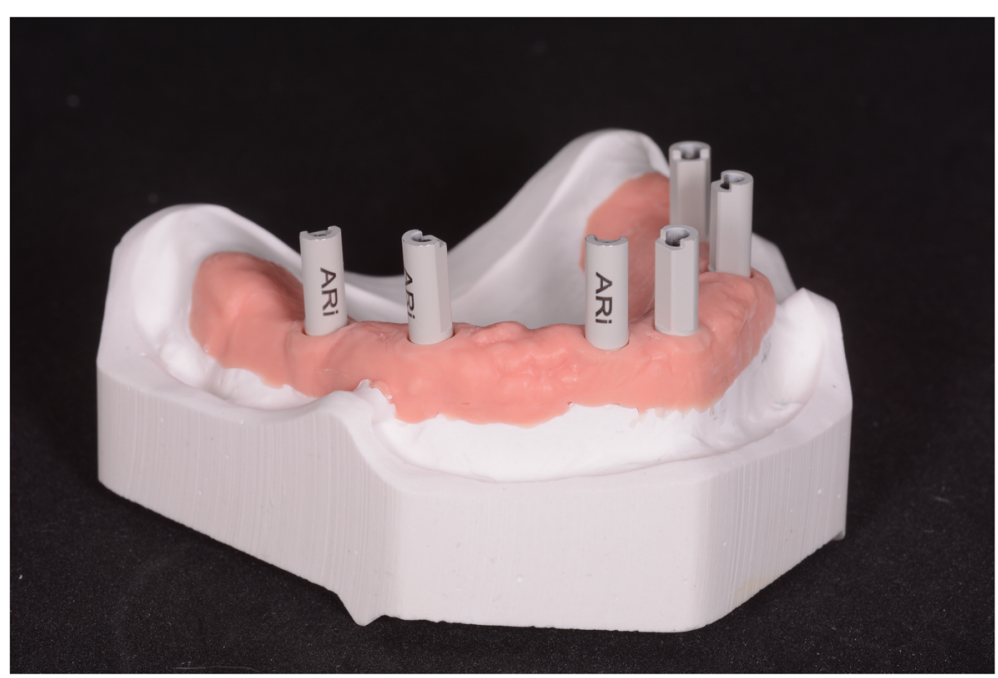

Fig. 1 In this in vitro study, a type IV gypsum model was used. This model represented a totally edentulous maxilla with 6 implant analogues in positions \#11,\#14,\#16, \#21, \#24 and \#26 (right and left central incisors, first premolars and first molars) and high-precision non-reflective polyether-ether-ketone (PEEK) SBs (Megagen ${ }^{\oplus}$, Daegu, South Korea) screwed on 
After the preparation of the desktop RM was completed, a single operator with over 10 years of experience with intraoral scanning (FGM) began to capture the scans with each of the IOSs in the study. All scans were taken in a 2-month period (January-February 2020) with the latest acquisition software available for each IOS at that time. The main characteristics of the IOSs used in this study are summarised in Table 1 . In all, the operator captured 10 scans for each IOS. The scans had to include the entire area of the pink gum and the 6 different SBs in full. To minimise the potential effects of fatigue, the sequence of scan capture with the different IOSs was randomised. The scans were spaced from each other by a rest period of $5 \mathrm{~min}$ for the operator. In all cases, the operator started from the posterior sectors (right or left) and proceeded along the arch with a zig-zag technique. As reported in previous studies [14, 27], this technique provided for a slow and constant advancement of the scan along the arch, starting from the buccal area and then moving occlusally and palatally, and returning to the buccal area: an arch was described above the pink gum and implant SBs. All scans were captured in the same environmental conditions, in a room moderately lit by sunlight with a temperature of $21{ }^{\circ} \mathrm{C}$, humidity of $45 \%$ and air pressure of $750 \pm 5 \mathrm{~mm}$. Ten virtual models were captured for each IOS, for a total of 120 STL files. These files were saved in dedicated folders, labelled with the IOS name and progressively numbered from 1 to 10 .

\section{Outcome variables}

Three different evaluations were performed using the RM acquired with the desktop scanner and the models derived from the different IOSs: a mesh/mesh evaluation and a nurbs/nurbs evaluation, to compute the overall general trueness of the intraoral scanning models, and the evaluation of the linear and cross distances between the different SBs, for analysis of the local trueness of the intraoral scanning models. The latter evaluation used the STL files generated during the nurbs/nurbs evaluation. The evaluation of the overall trueness with the mesh/mesh and nurbs/nurbs methods (overall general trueness) was performed using reverse engineering software (Studio ${ }^{\circ}$, Geomagics, Morrisville, NC, USA) by the same experienced operator (FGM) who captured all the scans. The evaluation of the distances between the SBs was performed by another operator (MB) with many years of experience with 3D calculation software, using different software (Magics ${ }^{\circ}$, Materialise, Leuven, Belgium).

\section{Mesh/mesh evaluation}

This evaluation was based exclusively on the meshes (STL files) generated by scanning with the desktop

Table 1 Features of the IOSs investigated in this study

\begin{tabular}{|c|c|c|c|}
\hline Name & Manufacturer & Acquisition technology & Output files \\
\hline $\begin{array}{l}\text { ITERO ELEMENTS } \\
5 D^{\oplus}\end{array}$ & $\begin{array}{l}\text { Align Technologies, San Josè, } \\
\text { CA, USA }\end{array}$ & Parallel Confocal Microscopy & $\begin{array}{l}\text { 3ds (proprietary format); ply and stl } \\
\text { (open formats) }\end{array}$ \\
\hline PRIMESCAN $^{\circledast}$ & Dentsply Sirona, York, PN, USA & $\begin{array}{l}\text { High-resolution Sensors and Shortwave Light } \\
\text { with Optical High Frequency Contrast Analysis } \\
\text { for Dynamic Deep Scan ( } 20 \text { mm) }\end{array}$ & $\begin{array}{l}\text { dxd (proprietary format) with possibility to } \\
\text { export .stl files (open } \\
\text { format) with Cerec Connect }{ }^{\circledR}\end{array}$ \\
\hline $\mathrm{OMNICAM}^{\oplus}$ & & Optical Triangulation and Confocal Microscopy & $\begin{array}{l}\text { cs3, sdt, cdt, idt (proprietary format) with } \\
\text { possibility to export .stl files (open format) } \\
\text { with Cerec Connect }{ }^{\oplus}\end{array}$ \\
\hline CS $3700^{\circledR}$ & $\begin{array}{l}\text { Carestream Dental, Atlanta, } \\
\text { GA, USA }\end{array}$ & $\begin{array}{l}\text { Active Triangulation with Smart-shade Matching } \\
\text { via Bidirectional Reflectance Distribution Function }\end{array}$ & $\begin{array}{l}\text { dcm (proprietary format); ply and stl } \\
\text { (open formats) }\end{array}$ \\
\hline $\operatorname{CS} 3600^{\circledR}$ & & LED light scanner -Active Speed 3D Video & $\begin{array}{l}\text { csz (proprietary format), ply and stl } \\
\text { (open formats) }\end{array}$ \\
\hline $\mathrm{TRIOS}^{\circledR}$ & $\begin{array}{l}\text { 3-Shape, Copenhagen, } \\
\text { Denmark }\end{array}$ & $\begin{array}{l}\text { Confocal Microscopy and Ultrafast Optical } \\
\text { Scanning }\end{array}$ & $\begin{array}{l}\mathrm{dcm} \text { (proprietary format), with possibility } \\
\text { to export stl files (open formats) with } \\
\text { Trios on Dental Desktop }{ }^{\circledR}\end{array}$ \\
\hline $\mathrm{i}-500^{\oplus}$ & Medit, Seoul, South Korea & 3D in Motion Video Technology & obj, ply and stl (open formats) \\
\hline EMERALD $S^{\otimes}$ & Planmeca, Helsinki, Finland & $\begin{array}{l}\text { Red, green and blue lasers- Projected Pattern } \\
\text { Triangulation }\end{array}$ & $\begin{array}{l}\text { 3oxz (proprietary format), ply and stl } \\
\text { (open formats) }\end{array}$ \\
\hline EMERALD ${ }^{\circledR}$ & & $\begin{array}{l}\text { Red, green and blue lasers- Projected Pattern } \\
\text { Triangulation }\end{array}$ & $\begin{array}{l}\text { 3oxz (proprietary format), ply and stl } \\
\text { (open formats) }\end{array}$ \\
\hline VIRTUOVIVO ${ }^{\oplus}$ & Dentalwings, Montreal, Canada & Blue laser-Multiscan Imaging Technology & $\begin{array}{l}\text { xorder (proprietary format); ply, stl } \\
\text { (open format) }\end{array}$ \\
\hline $\mathrm{DWIO}{ }^{\circledR}$ & & Blue laser-Multiscan Imaging Technology & $\begin{array}{l}\text { xorder (proprietary format); ply, stl } \\
\text { (open format) }\end{array}$ \\
\hline RUNEYES ${ }^{\circledR}$ & $\begin{array}{l}\text { Runeyes Ml, Ningbo, } \\
\text { Zhejiang, China }\end{array}$ & Synchronous 3D Video Quick Technology & obj, ply and stl (open formats) \\
\hline
\end{tabular}


scanner (RM) and the different IOSs, and took place as described in previous studies [14, 23, 24]. Each of the 10 meshes generated by each of the 12 IOSs was imported into reverse engineering software (Studio ${ }^{\circ}$, Geomagics, Morrisville, NC, USA), cut and trimmed with a single pre-formed template that included the pink gingiva area to be uniform in size, and then superimposed onto the RM captured with the desktop scanner, to evaluate the mean distance $( \pm$ standard deviation, SD) between the models. The superimposition consisted of two steps. First, the software performed a rough alignment of the IOS model over the RM, determined by three or more points that were identified on the surface of the same SBs present in the two models. This first rough alignment was subsequently perfected by the software through the application of a best-fit algorithm that allowed the surfaces to fully overlap. The parameters for this last superimposition were set with a minimum of 100 iterations per case, and the surface registration was completed by a robust-iterative-closest-point (RICP) algorithm. With this RICP algorithm, the distances between the RM and the IOS models were minimised using a point-to-plane method and the congruence between corresponding structures was calculated. Finally, the signed mean \pm SD of the distances in $\mu \mathrm{m}$ between the two superimposed models was calculated by the software, and a colorimetric map was generated to immediately visualise the distances between the models. The "3D deviation" function was used to generate the colorimetric map and quantify the distances between specific points, overall and in all space planes. The same setting for this map was used for all models, with the colour scale ranging from a maximum deviation of + $100 \mu \mathrm{m}$ to $-100 \mu \mathrm{m}$, and the best result given by the deviations between $+30 \mu \mathrm{m}$ and $-30 \mu \mathrm{m}$. The generated colour map indicated an outward (red) or inward (blue) deviation between the overlaid structures, while a minimal displacement $(<30 \mu \mathrm{m})$ was indicated by green. The data retrieved from these superimpositions for each IOS were saved in specific electronic datasheets (Excel ${ }^{\circ}$, Microsoft, Redmond, WA, USA) ready for statistical analysis, whereas the visual screenshots derived from each single superimposition were saved in another format (PowerPoint ${ }^{\circ}$, Microsoft, Redmond, WA, USA).

\section{Nurbs/nurbs evaluation}

This evaluation took place after replacing, within each mesh (the RM from the desktop scanner and all virtual models from the IOSs), the $6 \mathrm{SB}$ meshes with the corresponding SB library file, downloaded from the official library of the implant manufacturer (Megagen ${ }^{\circ}$, Daegu, South Korea). A new STL file was saved for each virtual model, which included only 6 SBs (nurbs files) free in the space, representing the implant positions. These nurbs files were used for superimpositions.
In detail, each of the meshes, already cut and trimmed as previously described, was opened with reverse engineering software (Studio $^{\circ}$, Geomagics, Morrisville, NC, USA). Then, 6 identical STL files were uploaded, those of the reference (nurbs) SB library file, provided directly from the implant library of the manufacturing company. At this point, these library files were superimposed onto each of the SBs present in the mesh, through the same superimposition procedure described above. First, a rough alignment of the library file was performed over the SB mesh; then, the surface superimposition was performed by the software, using the aforementioned RICP algorithm. This procedure was repeated for each single SB in the mesh, to obtain an STL file with the 6 SB library files in the correct position in the space. Then, the mesh was cancelled and a new file (nurbs file) with only the 6 SB library files in the proper position was saved. At the end of this procedure, which simulated what happens in the early stages of work in prosthetic CAD software (where the dental technician replaces the SB library file on the 3D reconstruction of the SB in the mesh, thus obtaining a hybrid model), it was possible to save files consisting of $6 \mathrm{SBs}$ from the implant library free in the space, in a position derived from that of SBs in the mesh. These nurbs files were saved in special folders, labelled with the different IOS names and progressively numbered from 1 to 10 , and were ready for analysis.

The analysis consisted of the superimposition of each of these nurbs STL files, derived from the different IOSs, over the RM nurbs. The procedure was the same as used in the mesh/mesh evaluation. Within the reverse engineering software Studio $^{\circ}$, Geomagics, Morrisville, NC, USA), the operator proceeded with an initial alignment of the nurbs file from the IOS onto the RM nurbs from the desktop scanner. This initial rough alignment took place by points, which were identified on the body of the scan abutments. Subsequently, the operator launched the best-fit algorithm, which perfected a surface alignment, generating the signed mean $( \pm S D)$ of the distance in $\mu \mathrm{m}$ between the two nurbs files. Also in this case, the distances were represented graphically with a colorimetric map. The same settings used in the mesh/mesh evaluation were used, except for the green area, which was defined for an error $<25 \mu \mathrm{m}$. Once again, the data retrieved from these superimpositions for each IOS were saved in specific electronic datasheets (Excel ${ }^{\circ}$, Microsoft, Redmond, WA, USA) ready for statistical analysis, whereas the visual screenshots derived from each single superimposition were saved in another format (PowerPoint $^{\circ}$, Microsoft, Redmond, WA, USA).

\section{Linear and cross distances}

A 3D calculation software (Magics ${ }^{\circ}$, Materialise, Leuven, Belgium) was used to compute the distances in $\mu \mathrm{m}$ between the different SBs. The calculation of the linear 


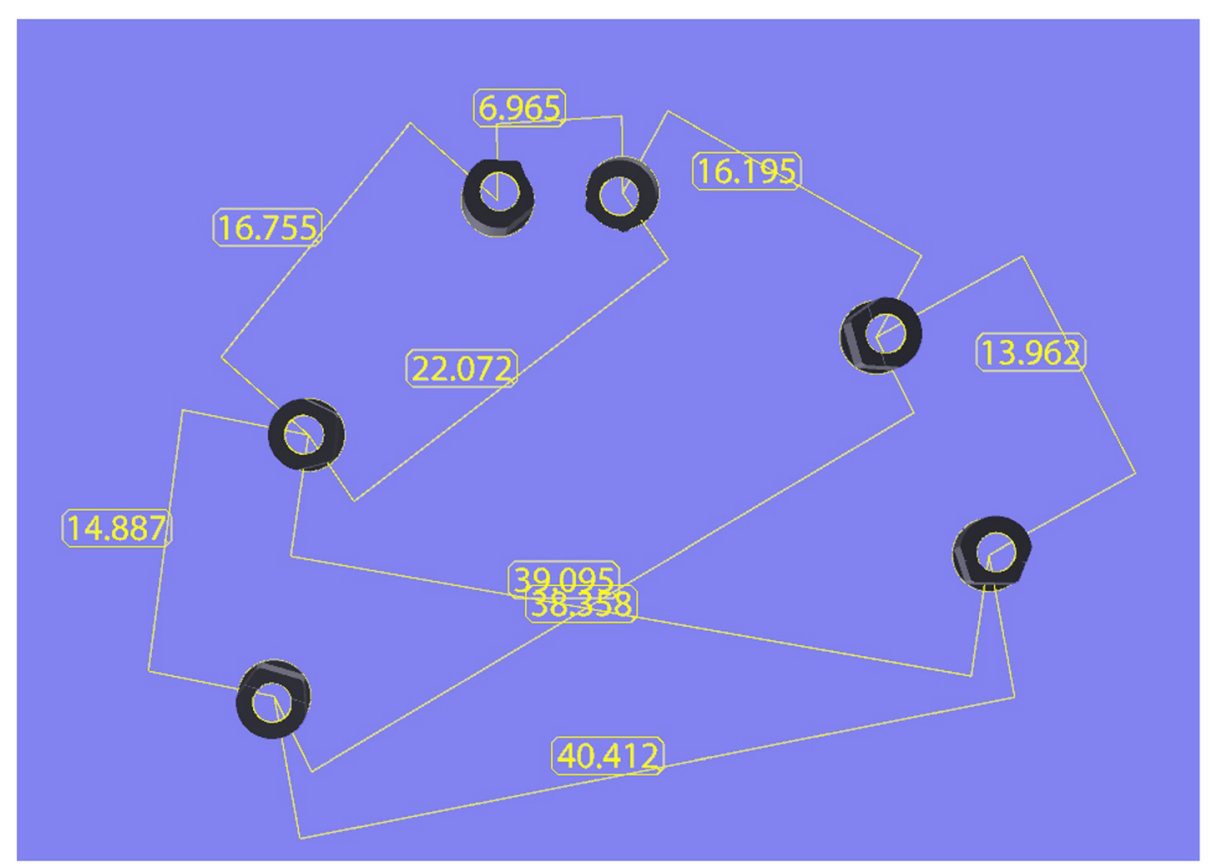

Fig. 2 Automatic evaluation of the linear and cross distances with the reference file, in $\mathrm{mm}$ (Magics Magics ${ }^{\circledR}$, Materialise, Leuven, Belgium)

and cross distances was first performed on the RM nurbs file, to define the reference values for each distance. The following linear distances (i.e. distances of the SBs during the progression of the scan) were computed: S1-S2, S2-S3, S3-S4, S4-S5 and S5-S6. The cross distances (i.e. distances between SBs with different positions in the arch) were computed as follows: S1-S6, S1-S5, S2-S6 and S3-S5. The distances were automatically computed by the software as distances between the centroids at the bases of the SBs (Fig. 2). Once the reference values for each single distance were computed and saved in a specific datasheet (Excel ${ }^{\circ}$, Microsoft, Redmond, WA, USA), the same computation was repeated for each nurbs file from each single IOS scan. Tables were generated with all values for each scan taken from each IOS, and these values were used for statistical analysis.

\section{Statistical analysis}

Data analysis and visualisation were performed using $R$ (version 3.6.3) environment for statistical computing ( $R$ Foundation for Statistical Computing, Vienna, Austria).

Table 2 Descriptive statistics (error in $\mu \mathrm{m}$, medians and quartiles, means and 95\% Cls) for mesh/mesh and nurbs/nurbs evaluations

\begin{tabular}{|c|c|c|c|c|}
\hline \multirow[t]{2}{*}{ Scanner } & \multicolumn{2}{|l|}{ Mesh/Mesh } & \multicolumn{2}{|l|}{ Nurbs/Nurbs } \\
\hline & Median $\left(Q_{1}-Q_{3}\right)$ & Mean $(95 \% \mathrm{Cl})$ & Median $\left(Q_{1}-Q_{3}\right)$ & Mean $(95 \% \mathrm{Cl})$ \\
\hline $\operatorname{CS} 3600^{\circledR}$ & $35.5(31.5-46.0)$ & $36.5[29.8 ; 44.6]$ & $23.5(21.5-34.0)$ & $24.4[18.0 ; 33.1]$ \\
\hline CS $3700^{\circledR}$ & $29.5(27.2-34.5)$ & $30.4[26.7 ; 34.5]$ & $22.0(19.8-24.8)$ & $21.9[19.3 ; 25.0]$ \\
\hline $\mathrm{DWIO}^{\oplus}$ & $90.5(84.2-110.8)$ & $98.4[84.4 ; 114.8]$ & $65.0(51.0-82.2)$ & $69.9[55.0 ; 88.9]$ \\
\hline EMERALD $^{\circledast}$ & $76.0(67.5-81.0)$ & $76.1[68.1 ; 85.1]$ & $54.5(40.8-60.5)$ & $51.9[43.5 ; 61.8]$ \\
\hline EMERALD $\mathbf{S}^{\circledast}$ & $51.0(46.5-54.8)$ & $52.9[46.8 ; 59.7]$ & $37.0(31.2-40.8)$ & $36.8[31.1 ; 43.6]$ \\
\hline ITERO ELEMENTS 5D ${ }^{\circledR}$ & $32.0(30.2-33.8)$ & $31.4[29.2 ; 33.8]$ & $15.0(14.2-16.8)$ & $16.1[12.9 ; 20.1]$ \\
\hline MEDIT I-500 ${ }^{\circledR}$ & $31.5(29.0-33.8)$ & $32.2[28.4 ; 36.6]$ & $20.5(17.5-25.8)$ & $20.8[16.9 ; 25.5]$ \\
\hline OMNICAM $^{\circledast}$ & $80.5(72.2-90.8)$ & $79.6[66.9 ; 94.6]$ & $56.0(33.2-62.5)$ & $47.0[33.7 ; 65.7]$ \\
\hline PRIMESCAN $^{\circledR}$ & $39.5(35.5-41.8)$ & $38.4[35.8 ; 41.2]$ & $19.0(17.0-23.8)$ & $19.3[16.3 ; 22.9]$ \\
\hline RUNEYES $^{\circledast}$ & $41.5(33.5-56.0)$ & $44.4[34.9 ; 56.5]$ & $32.5(26.0-43.0)$ & $33.9[26.4 ; 43.6]$ \\
\hline TRIOS $3^{\circledR}$ & $36.0(35.2-38.5)$ & $36.4[33.9 ; 39.1]$ & $20.5(19.0-23.0)$ & $20.2[18.1 ; 22.7]$ \\
\hline VIRTUO VIVO ${ }^{\circledR}$ & $38.0(35.2-42.2)$ & $43.8[33.6 ; 57.1]$ & $28.0(26.2-33.2)$ & $32.0[24.4 ; 42.0]$ \\
\hline
\end{tabular}




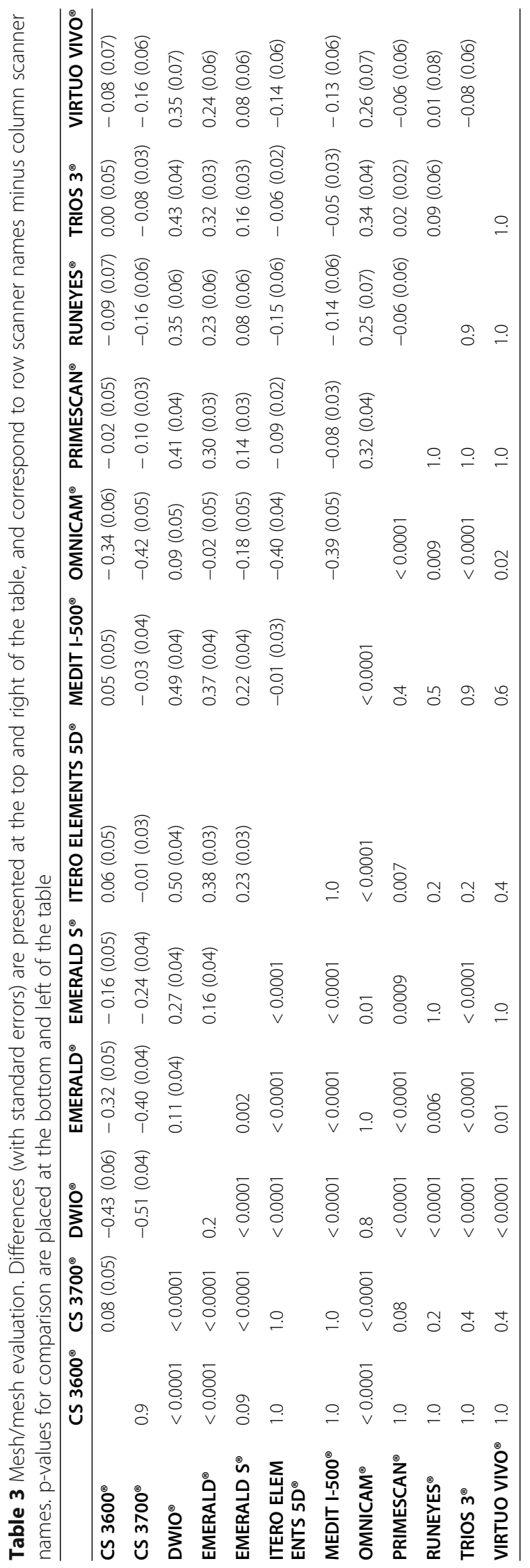




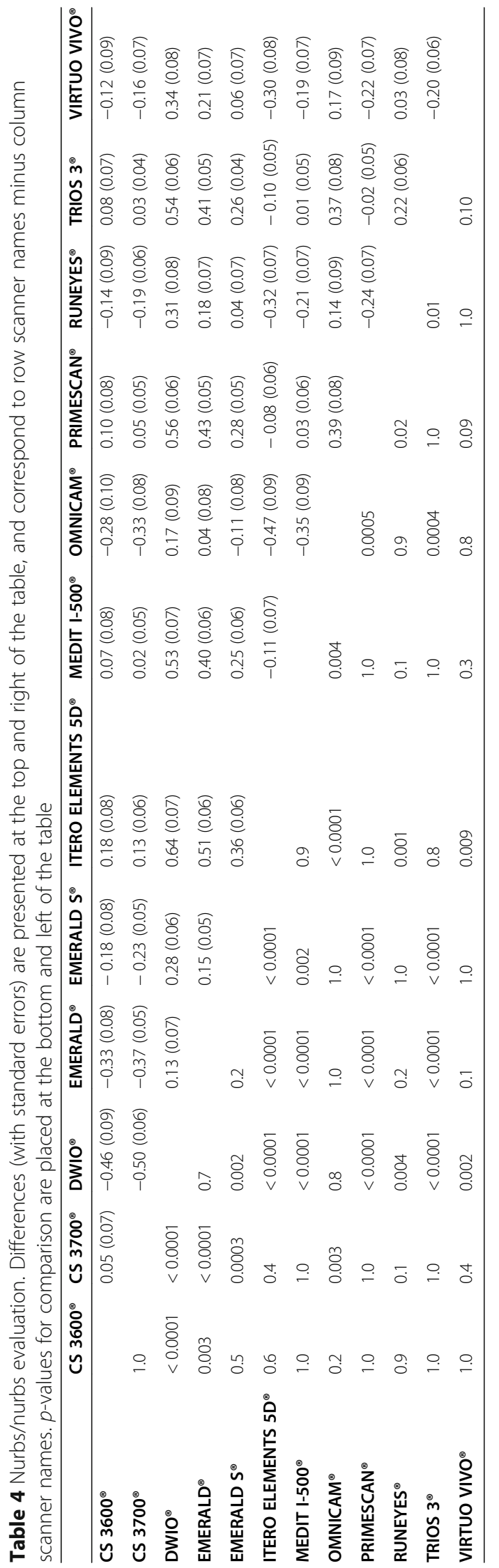




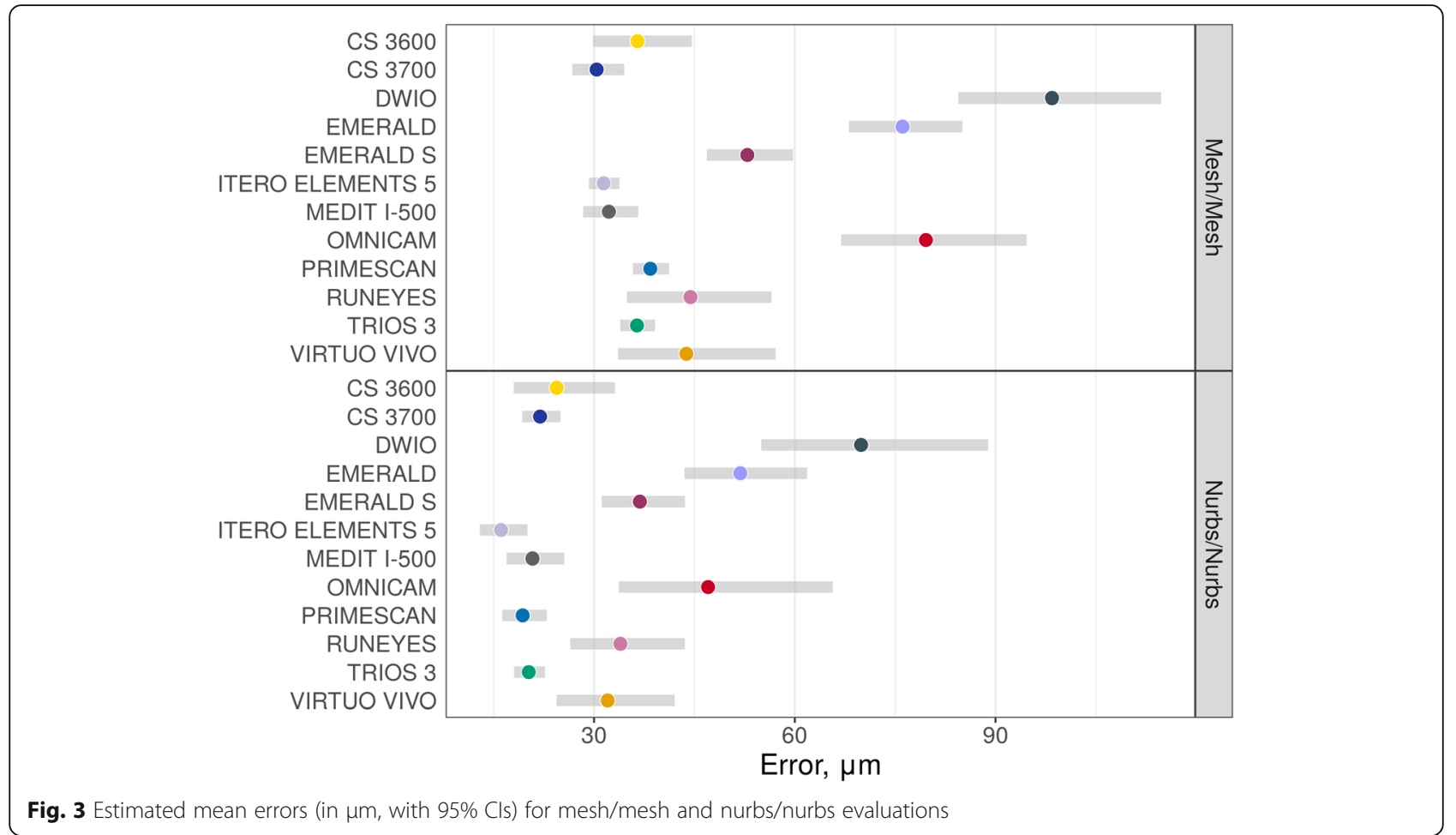

Descriptive statistics for quantitative variables were presented as medians (1st and 3rd quartiles; Tables 2 and 3) and medians (median absolute deviations; Table 4). Before regression modelling, mesh/mesh and nurbs/nurbs distance were $\log _{10}$-transformed (due to substantial right skewness on the raw scale); means and corresponding 95\% confidence intervals (CI) were estimated using models then re-transformed to the raw scale (Tables 2 and 3). Linear and cross distances were used in raw scale. Linear models were used to estimate and compare mean mesh/mesh and nurbs/nurbs errors (on the $\log _{10^{-}}$ scale) between scanners. The Sandwich standard error estimator was used to address heteroskedasticity, and the Satterthwaite method was used to approximate degrees of freedom. The Tukey method (implemented in emmeans 1.4.5) was used to adjust $p$-values. A linear mixed effects model (implemented in lme4 1.1-21) was used to estimate and compare mean linear and cross distances (on raw scale) between scanners (to account hierarchy: scanner $\rightarrow$ pairs of SBs). The Sandwich clusterrobust variance-covariance matrix estimator was used to address heteroskedasticity, and the Satterthwaite method was again used to approximate degrees of freedom. The Tukey method was used to adjust p-values.

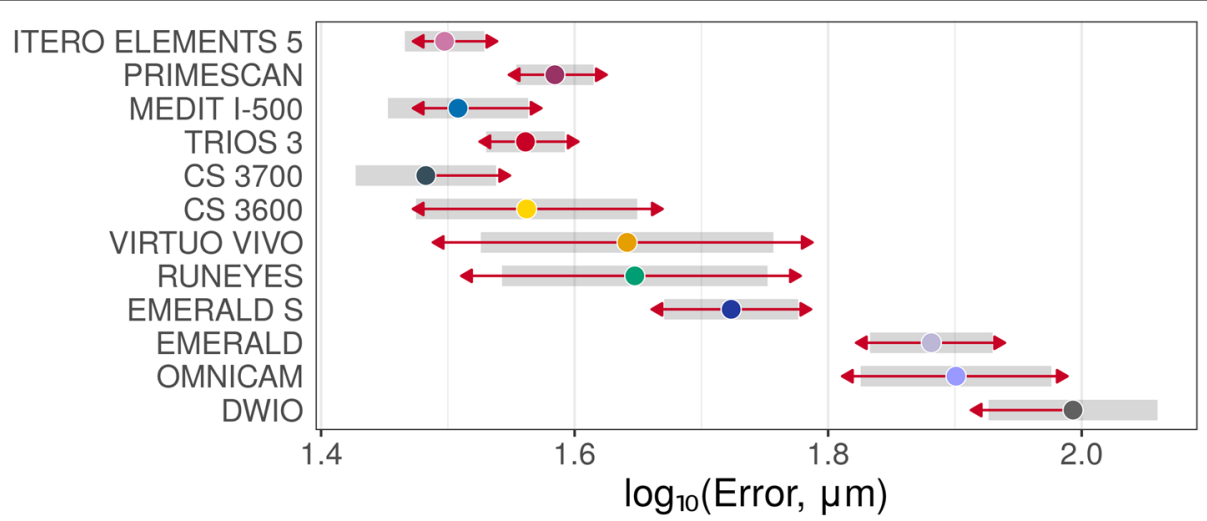

Fig. 4 Overall mesh/mesh evaluation. A log10 scale was used for the analysis. Log transformed values were represented on the $x$-axis. The overlap of red arrows between pairs of scanners indicates no statistically significant difference 


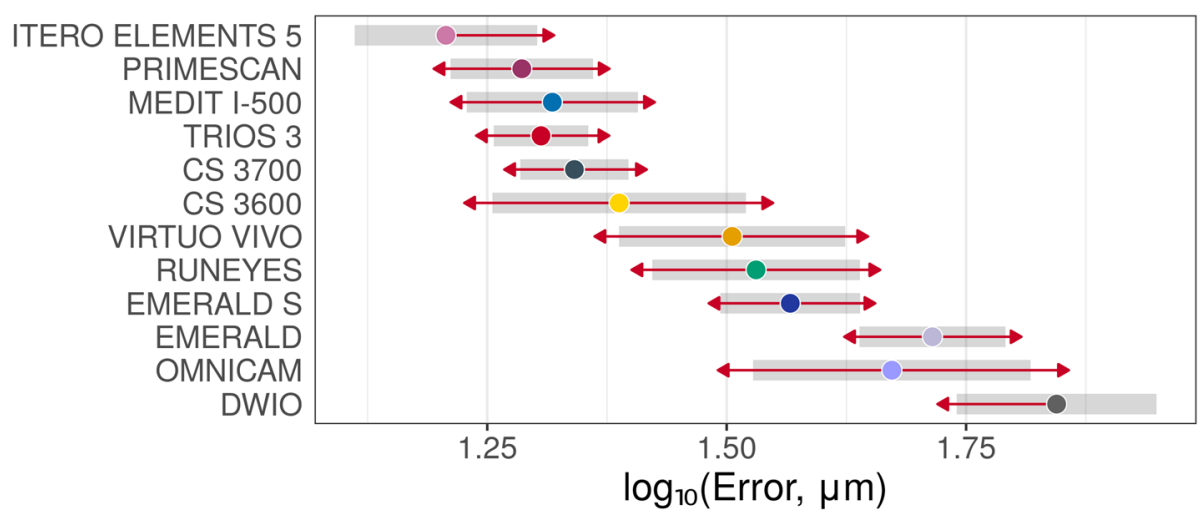

Fig. 5 Overall nurbs/nurbs evaluation. A log10 scale was used for the analysis. Log transformed values were represented on the $x$-axis. The overlap of red arrows between pairs of scanners indicates no statistically significant difference

\section{Results}

Descriptive statistics (medians and quartiles; means and 95\% CIs) for mesh/mesh and nurbs/nurbs errors are presented in Table 2. Estimated mean errors (with 95\% CIs - symmetrical on the log scale) on raw scales are presented in Figs. 3, 4 and 5. In thes latter two figures, the overlap of the red arrows between pairs of scanners indicates no statistically significant difference. A statistically significant difference was found among different scanner pairs.

Nurbs/nurbs errors were systematically lower than mesh/mesh errors, as evidenced in the scatter plot in Fig. 6 , as the test result for $\mathrm{H} 0: \beta_{1}=1$ (corresponds to model: nurbs $/$ nurbs $=\beta_{0}$ [different for each scanner - random intercept] $+1 \times$ mesh $/$ mesh): $\quad t=10.7, \quad$ noncentrality parameter $=1, \mathrm{df}=87.6, p<0.0001 . \quad \beta_{1}=1.21$ (95\% CI 1.10; 1.33). Pairwise differences in errors (on $\log _{10}$-scale/orders of differences with corresponding standard errors and $p$-values) with the different methods are presented in Tables 3 and 4.

With the mesh/mesh method, the best results were obtained by CS $3700^{\circ}$ (mean error $30.4 \mu \mathrm{m}$; 95\% CI 26.7-34.5 $\mu \mathrm{m}$ ) followed by ITERO ELEMENTS $5 \mathrm{D}^{\circ}$ (mean error $31.4 \mu \mathrm{m}$; 95\% CI $29.2-33.8 \mu \mathrm{m}$ ), i-500 (mean error $32.2 \mu \mathrm{m}$; 95\% CI 28.4-36.6 $\mu \mathrm{m}$ ); TRIOS $3^{\circ}$ (mean error $36.4 \mu \mathrm{m}$; 95\% CI 33.9-39.1 $\mu \mathrm{m}$ ), CS $3600^{\circ}$ (mean error $36.5 \mu \mathrm{m}$; 95\% CI 29.8-44.6 $\mu \mathrm{m}$ ), PRIMESCA $\mathrm{N}^{\circ} \quad$ (mean error $38.4 \mu \mathrm{m} ; \quad 95 \%$ CI $\left.35.8-41.2 \mu \mathrm{m}\right)$,

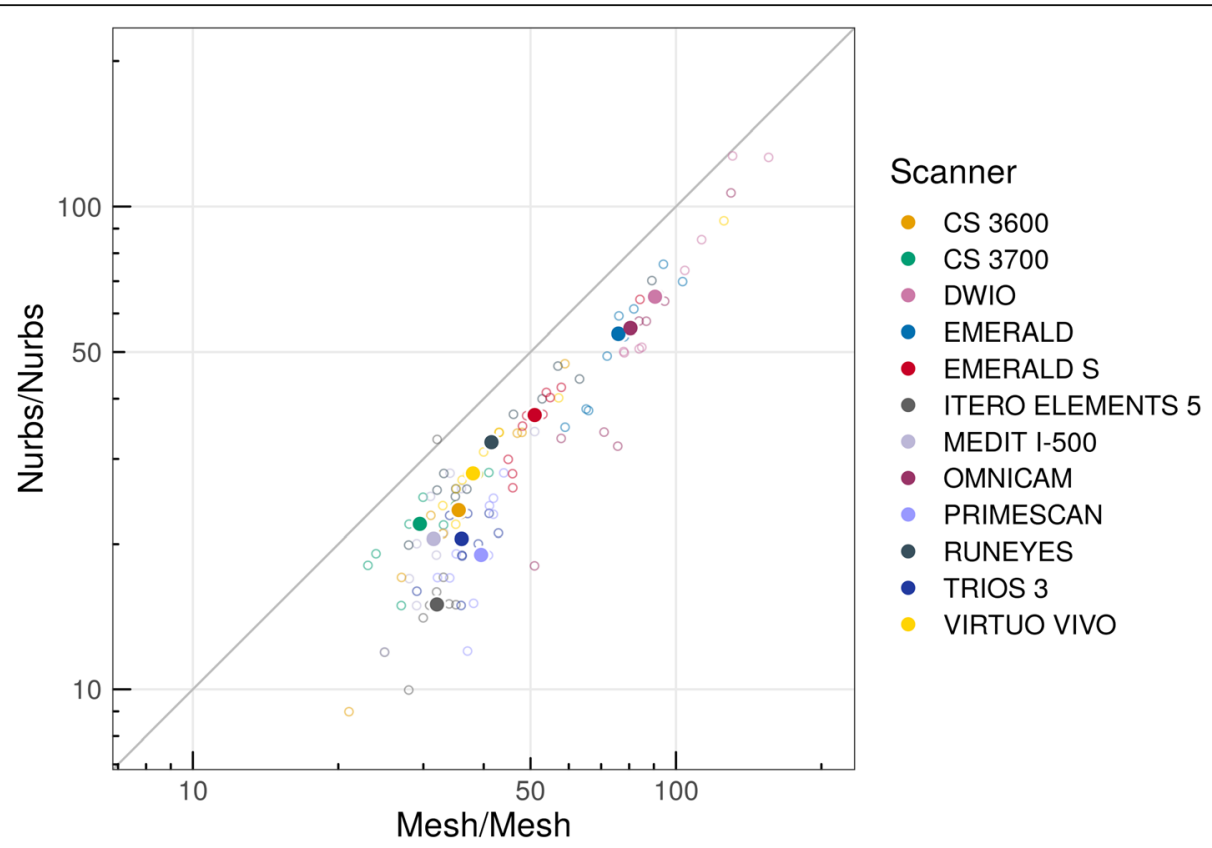

Fig. 6 Circles correspond to individual observations, filled dots - medians for each scanner. The scatter plot highlighted that nurbs/nurbs errors were systematically lower than mesh/mesh errors 


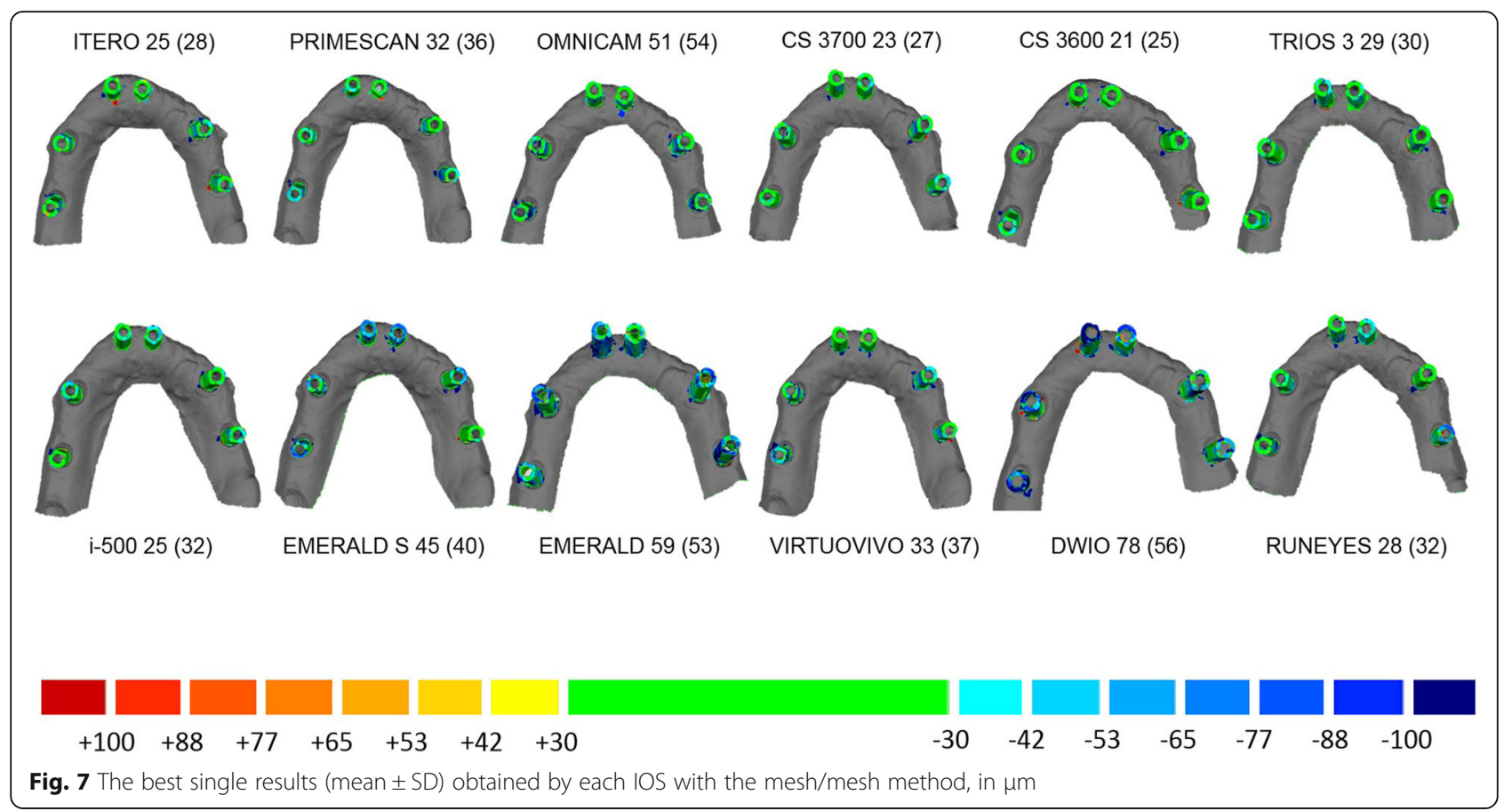

VIRTUO VIVO ${ }^{\circ}$ (mean error $43.8 \mu \mathrm{m}$; 95\% CI 33.6$57.1 \mu \mathrm{m}$ ), RUNEYES ${ }^{\oplus}$ (mean error $44.4 \mu \mathrm{m}$; 95\% CI 34.9-56.5 $\mu \mathrm{m}$ ), EMERALD $\mathrm{S}^{\odot}$ (mean error $52.9 \mu \mathrm{m}$; 95\% CI 46.8-59.7 $\mu \mathrm{m}$ ), EMERALD ${ }^{\circ}$ (mean error $76.1 \mu \mathrm{m}$; 95\% CI 68.1-85.1 $\mu \mathrm{m}$ ), OMNICAM $^{\circ}$ (mean error $79.6 \mu \mathrm{m}$; 95\% CI 66.9-94.6 $\mu \mathrm{m}$ ) and $\mathrm{DWIO}^{\circ}$ (mean error $98.4 \mu \mathrm{m} ; 95 \%$ CI $84.4-114.8 \mu \mathrm{m})$. The best single results obtained by each IOS with the mesh/mesh method were summarized in Fig. 7. Statistically significant differences were found between the IOSs, as reported at the bottom and left of Table 3.

With the nurbs/nurbs method, the best results were obtained by ITERO ELEMENTS $5 \mathrm{D}^{\circ}$ (mean error $16.1 \mu \mathrm{m} ; 95 \%$ CI 12.9-20.1 $\mu \mathrm{m})$, followed by PRIMESCA $\mathrm{N}^{\bullet}(19.3 \mu \mathrm{m} ; 95 \%$ CI $16.3-22.9 \mu \mathrm{m})$, TRIOS $3^{\circ}$ (mean error $20.2 \mu \mathrm{m}$; 95\% CI 18.1-22.7 $\mu \mathrm{m}$ ), i-500 ${ }^{\circ}$ (mean error $20.8 \mu \mathrm{m} ; 95 \%$ CI 16.9-25.5 $\mu \mathrm{m}$ ), CS $3700^{\circ}$ (mean error $21.9 \mu \mathrm{m}$; 95\% CI 19.3-25.0 $\mu \mathrm{m}$ ), CS $3600^{\circ}$ (mean error

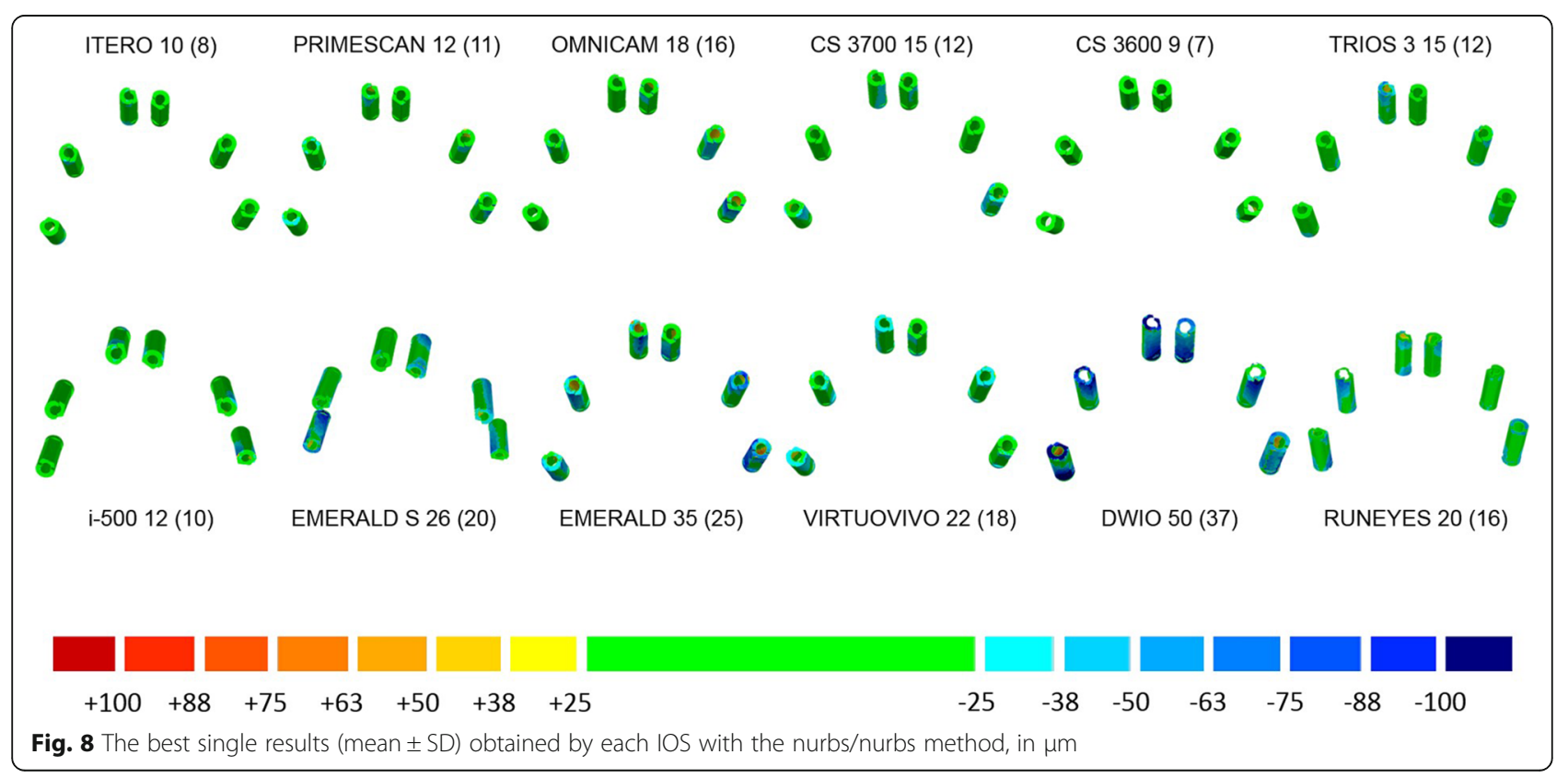


Table 5 Descriptive statistics (error in $\mu \mathrm{m}$, medians and quartiles, means and 95\% Cls) for linear and cross distances

\begin{tabular}{|c|c|c|c|c|c|c|}
\hline \multirow[t]{2}{*}{ Scanner } & \multicolumn{3}{|l|}{ Linear distances } & \multicolumn{3}{|l|}{ Cross distances } \\
\hline & Median $\left(Q_{1}-Q_{3}\right)^{a}$ & $\begin{array}{l}\text { Median }\left(\mathrm{Q}_{1-}\right. \\
\left.\mathrm{Q}_{3}\right)^{\mathbf{b}}\end{array}$ & Mean $(95 \% \mathrm{Cl})^{c}$ & Median $\left(Q_{1}-Q_{3}\right)^{a}$ & $\begin{array}{l}\text { Median }\left(\mathrm{Q}_{1-}\right. \\
\left.\mathrm{Q}_{3}\right)^{\mathbf{b}}\end{array}$ & Mean $(95 \% \mathrm{Cl})^{\mathrm{c}}$ \\
\hline$\overline{C S} 3600^{\circ}$ & $0.0(-9.2-8.0)$ & $8.0(4.0-19.0)$ & $-3.0[-15.7 ; 9.7]$ & $60.5(-2.5-109.2)$ & $62.5(19.2-109.2)$ & $70.9[-3.0 ; 144.8]$ \\
\hline $\operatorname{CS} 3700^{\circ}$ & $5.5(-15.8-19.5)$ & $19.0(10.0-26.8)$ & $1.2[-15.3 ; 17.7]$ & $5.5(-25.0-39.2)$ & $35.0(20.5-50.0)$ & $15.0[-7.2 ; 37.2]$ \\
\hline $\mathrm{DW} \mid \mathrm{O}^{\oplus}$ & $\begin{array}{l}-58.5(-104.5-- \\
36.2)\end{array}$ & $58.5(36.2-104.5)$ & $\begin{array}{l}-76.5[-109.8 \\
-43.3]\end{array}$ & $-12.5(-119.0-55.5)$ & $\begin{array}{l}111.0(46.5- \\
230.2)\end{array}$ & $-20.0[-86.8 ; 46.8]$ \\
\hline EMERALD $^{\circledR}$ & $-35.0(-69.8--11.8)$ & $41.0(16.0-69.8)$ & $-40.1[-67.4 ;-12.7]$ & $-24.0(-112.8-40.8)$ & $\begin{array}{l}103.0(34.5- \\
122.0)\end{array}$ & $-27.6[-105.9 ; 50.8]$ \\
\hline EMERALD S ${ }^{\oplus}$ & $-38.0(-51.8--19.2)$ & $38.0(19.2-51.8)$ & $\begin{array}{l}-41.7[-67.9 ;- \\
15.6]\end{array}$ & $\begin{array}{l}-131.0(-220.8-- \\
97.2)\end{array}$ & $\begin{array}{l}131.0(97.2- \\
220.8)\end{array}$ & $\begin{array}{l}-156.0[-216.3 ;- \\
95.7]\end{array}$ \\
\hline $\begin{array}{l}\text { ITERO ELEMENTS } \\
5 D^{\oplus}\end{array}$ & $0.0(-6.0-13.0)$ & $11.0(4.0-17.8)$ & $-1.2[-19.5 ; 17.2]$ & $8.5(-18.2-46.8)$ & $36.0(14.5-57.2)$ & $13.9[-3.7 ; 31.5]$ \\
\hline MEDIT I-500 & $-0.5(-11.5-5.8)$ & $8.0(3.0-16.8)$ & $-2.2[-12.9 ; 8.6]$ & $-6.0(-27.5-23.5)$ & $27.0(15.5-54.0)$ & $-9.6[-20.3 ; 1.2]$ \\
\hline $\mathrm{OMNICAM}^{\circledast}$ & $-8.5(-30.5-10.5)$ & $23.0(9.8-52.0)$ & $-6.6[-26.5 ; 13.3]$ & $15.0(-48.5-138.2)$ & $88.5(27.5-150.2)$ & $52.3[-12.0 ; 116.7]$ \\
\hline PRIMESCAN ${ }^{\circledast}$ & $3.5(-2.0-9.0)$ & $6.5(3.0-11.0)$ & $-0.8[-8.0 ; 6.4]$ & $41.5(7.0-86.8)$ & $41.5(14.8-86.8)$ & $50.2[6.9 ; 93.6]$ \\
\hline RUNEYES ${ }^{\circledast}$ & $18.5(-1.0-33.2)$ & $23.0(15.0-34.8)$ & $16.4[3.0 ; 29.8]$ & $114.0(49.2-216.8)$ & $\begin{array}{l}114.0(49.2- \\
216.8)\end{array}$ & $142.4[64.0 ; 220.9]$ \\
\hline TRIOS $3^{\oplus}$ & $-30.0(-37.0--19.2)$ & $30.0(22.0-37.0)$ & $-25.4[-41.8 ;-9.0]$ & $-78.5(-124.2--50.0)$ & $78.5(56.0-124.2)$ & $-83.7[-122.4 ;-45.1]$ \\
\hline VIRTUO VIVO ${ }^{\circledast}$ & $-14.0(-25.5-0.5)$ & $15.5(6.2-25.5)$ & $-18.0[-35.9 ;-0.1]$ & $-51.0(-85.5--11.0)$ & $55.5(30.2-87.8)$ & $-74.4[-85.7 ;-63.0]$ \\
\hline
\end{tabular}

${ }^{\mathrm{a}}$ Median (interquartile range) error calculated on raw data

${ }^{\mathrm{b}}$ Median (interquartile range) absolute error

${ }^{c}$ Mean error $(95 \% \mathrm{Cl})$ estimated using linear mixed effects models

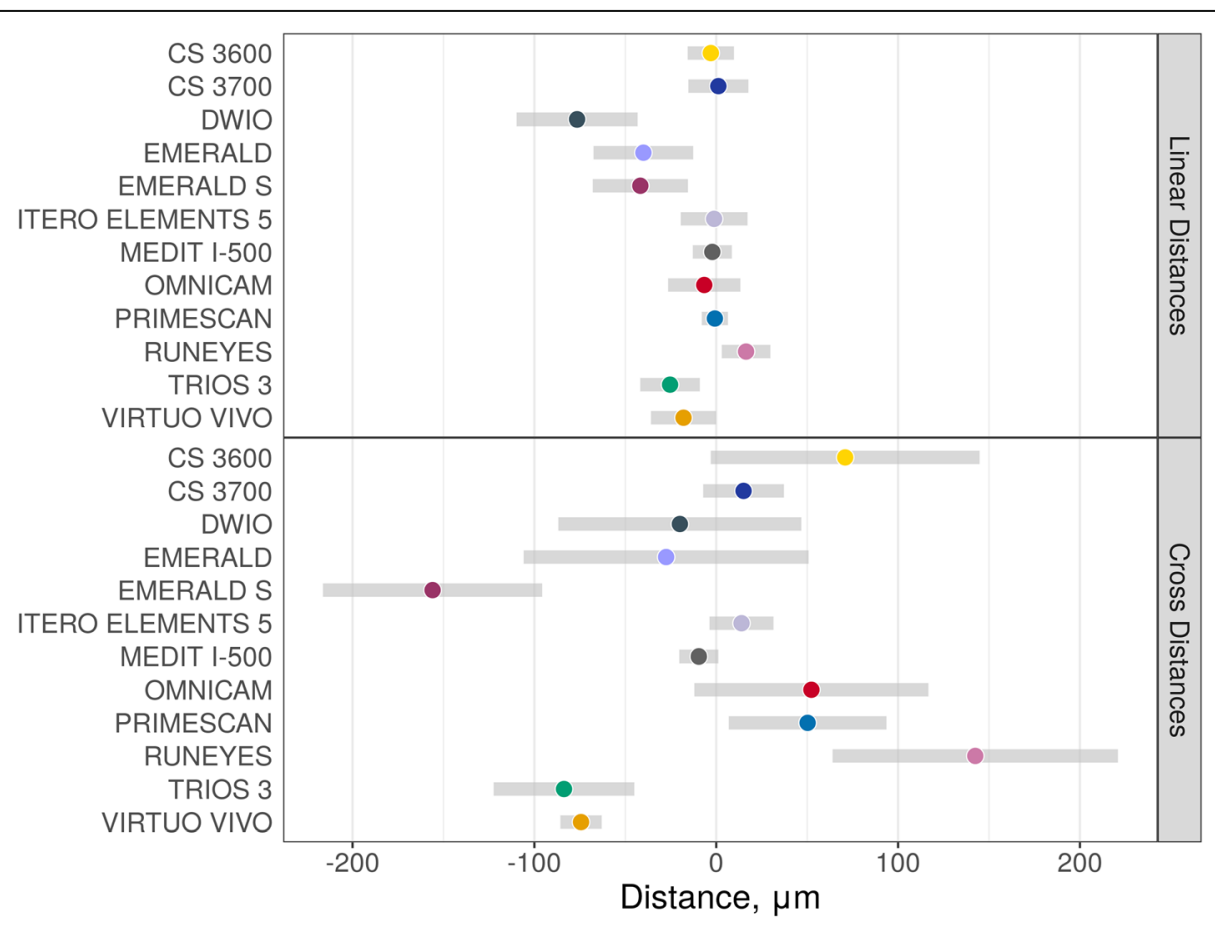

Fig. 9 Estimated mean errors (in $\mu \mathrm{m}$, with 95\% Cls) for linear and cross distances 


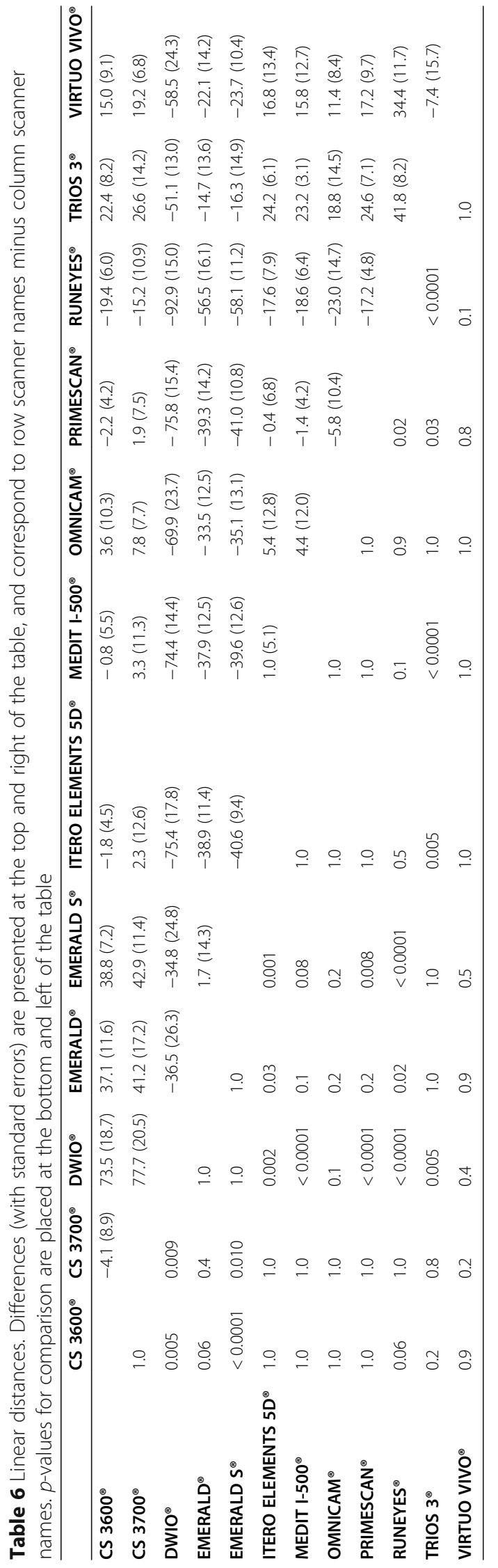




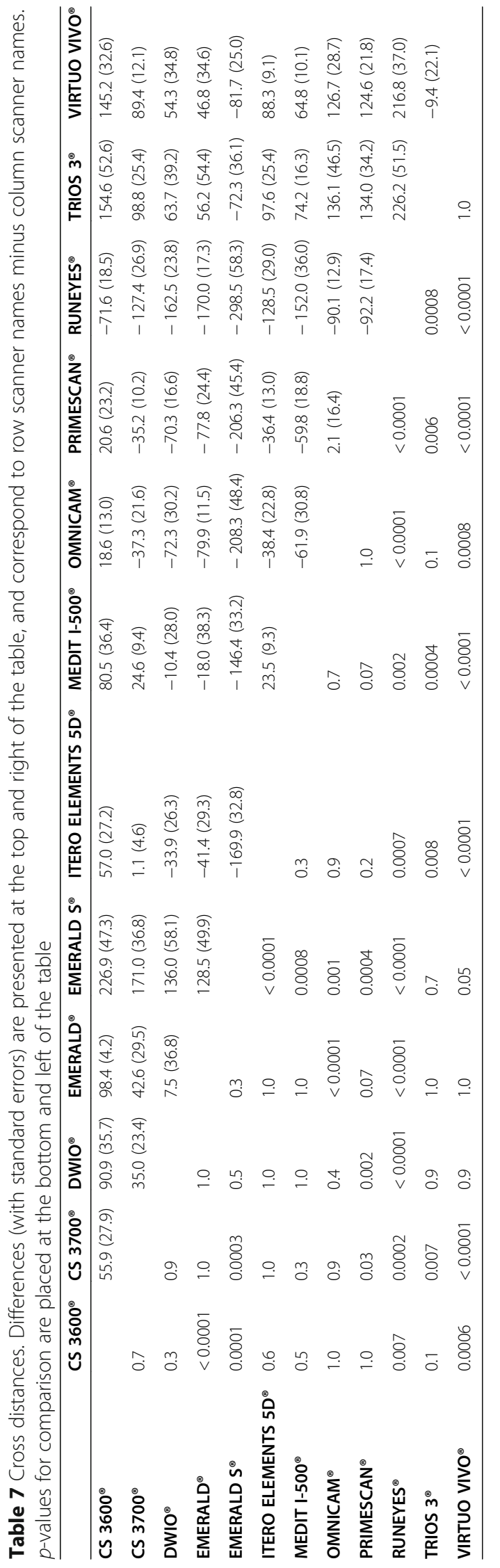


Table 8 Medians and median absolute deviations (from median, MAD)

\begin{tabular}{|c|c|c|}
\hline Scanner & Linear distances median (MAD) & Cross distances median (MAD) \\
\hline$\overline{C S} 3600^{\circledR}$ & $0.0(11.9)$ & $60.5(89.0)$ \\
\hline CS $3700^{\circledR}$ & $5.5(23.7)$ & $5.5(49.7)$ \\
\hline $\mathrm{DWIO}^{\circledR}$ & $-58.5(55.6)$ & $-12.5(151.2)$ \\
\hline EMERALD $^{\circledast}$ & $-35.0(40.0)$ & $-24.0(126.8)$ \\
\hline EMERALD $S^{\circledast}$ & $-38.0(27.4)$ & $-131.0(60.0)$ \\
\hline ITERO ELEMENTS $5^{\circledR}$ & $0.0(16.3)$ & $8.5(48.2)$ \\
\hline MEDIT I-500 ${ }^{\circledR}$ & $-0.5(11.9)$ & $-6.0(40.0)$ \\
\hline OMNICAM $^{\circledR}$ & $-8.5(31.1)$ & $15.0(126.8)$ \\
\hline PRIMESCAN $^{\circledR}$ & $3.5(8.2)$ & $41.5(57.8)$ \\
\hline RUNEYES $^{\circledast}$ & $18.5(23.7)$ & $114.0(108.2)$ \\
\hline TRIOS $3^{\circledast}$ & $-30.0(13.3)$ & $-78.5(56.3)$ \\
\hline VIRTUO VIVO ${ }^{\circledR}$ & $-14.0(20.8)$ & $-51.0(56.3)$ \\
\hline
\end{tabular}

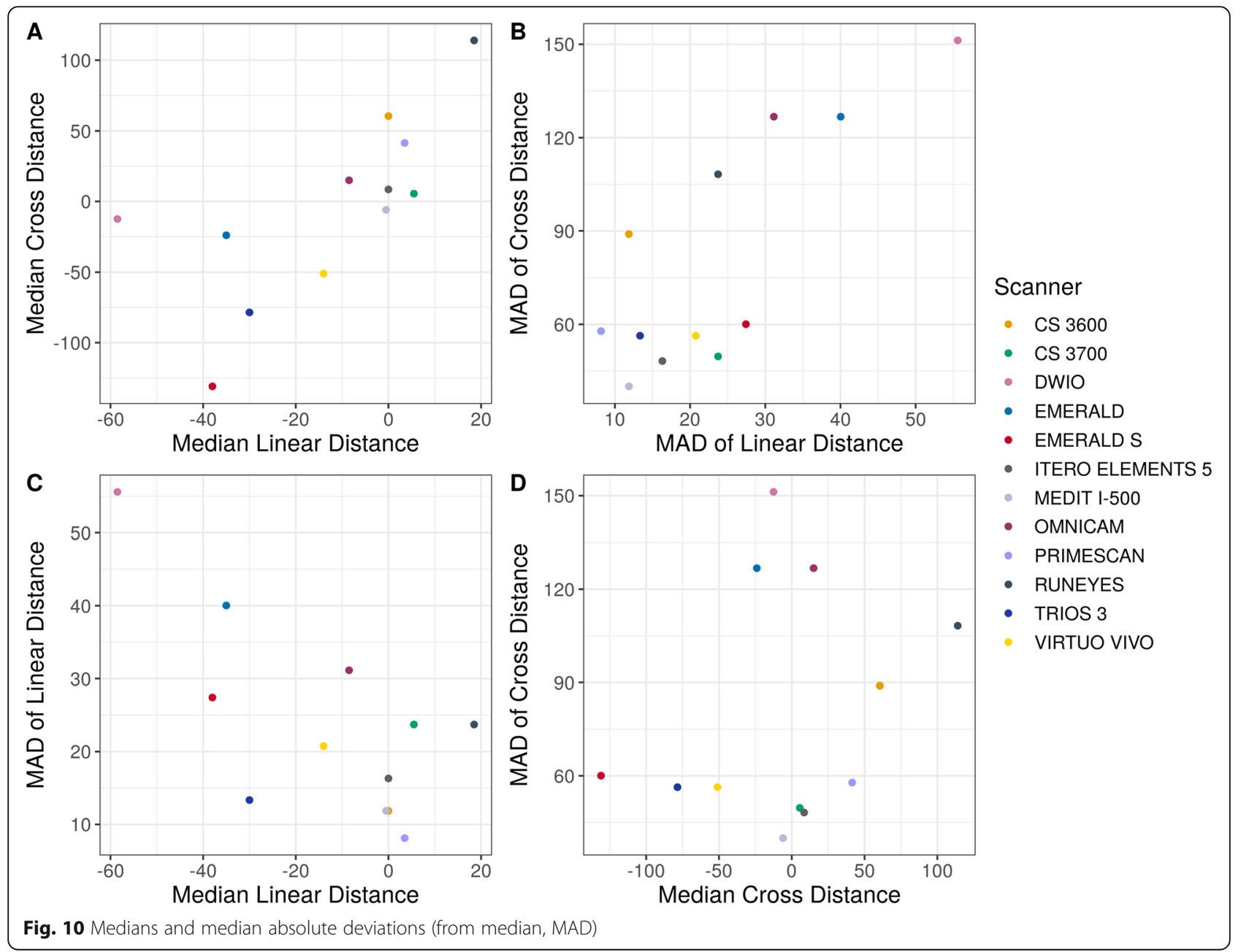




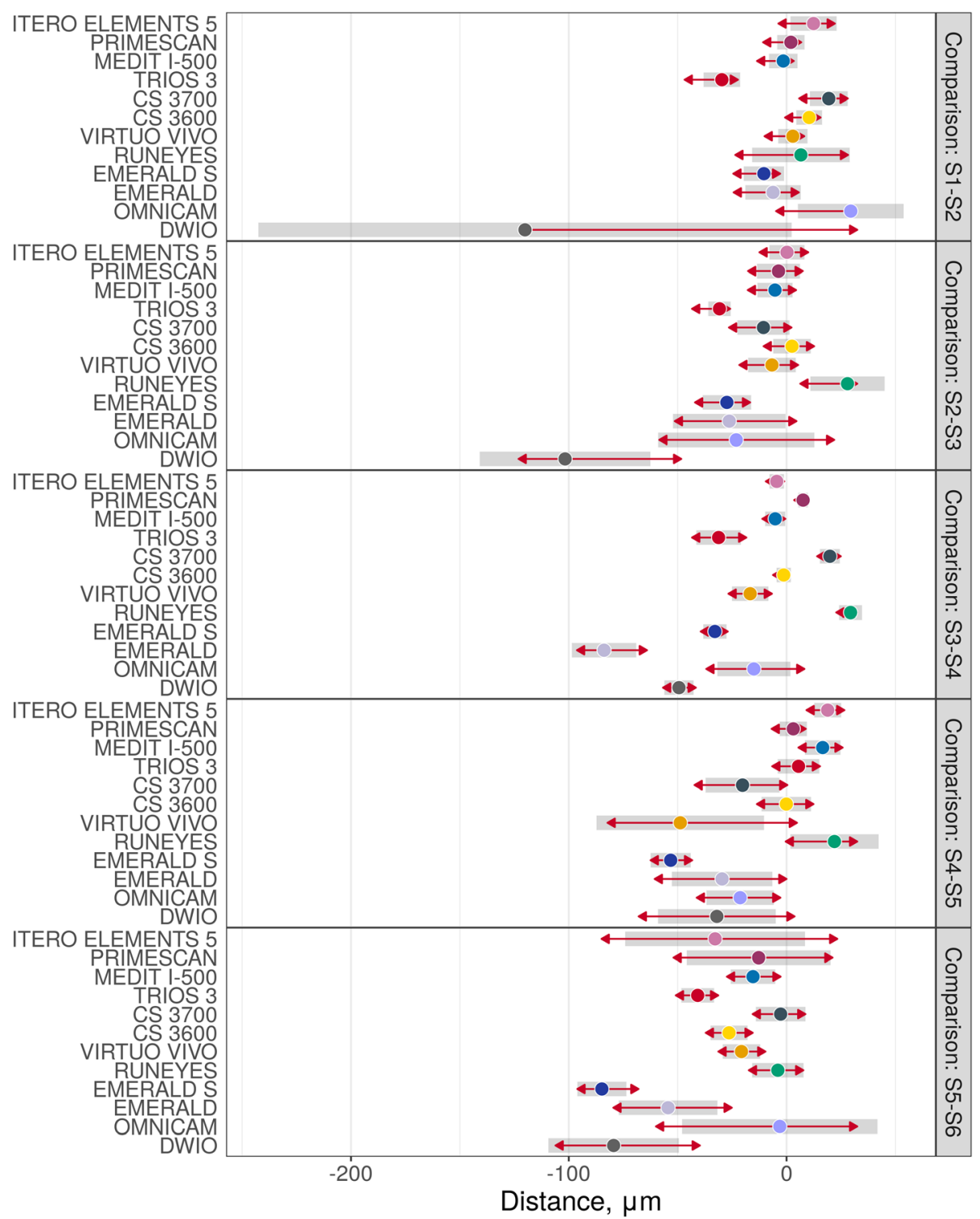

Fig. 11 Linear distances: mean error (Cl 95\%) and comparison between the different intraoral scanners. The overlap of the red arrows between pairs of scanners indicates no statistically significant difference

$24.4 \mu \mathrm{m} ; 95 \%$ CI 18.0-33.1 $\mu \mathrm{m})$, VIRTUO VIVO ${ }^{\circ}$ (mean error $32.0 \mu \mathrm{m}$; 95\% CI 24.4-42.0 $\mu \mathrm{m}$ ), RUNEYES ${ }^{\oplus}$ (mean error $33.9 \mu \mathrm{m}$; 95\% CI 26.4-43.6 $\mu \mathrm{m})$, EMERALD $\mathrm{S}^{\odot}$ (mean error $36.8 \mu \mathrm{m}$; 95\% CI 31.1-43.6 $\mu \mathrm{m}$ ), OMNI$\mathrm{CAM}^{\ominus}$ (mean error $47.0 \mu \mathrm{m}$; 95\% CI 33.7-65.7 $\mu \mathrm{m}$ ), EMERALD $^{\circ}$ (mean error $51.9 \mu \mathrm{m}$; 95\% CI 43.5-61.8 $\mu \mathrm{m}$ ) and DWIO $^{\circ}$ (mean error $69.9 \mu \mathrm{m}$; 95\% CI 55.0$88.9 \mu \mathrm{m})$. The best single results obtained by each IOS with the nurbs/nurbs method were summarized in Fig. 8. Statistically significant differences were found between the IOSs, as reported at the bottom and left of Table 4.

Descriptive statistics (medians and quartiles, means and 95\% CIs) for linear and cross distances are presented in Table 5. Estimated mean distances (with 95\%
CIs) on raw scales are presented in Fig. 9. Pairwise differences in distances (on raw scales with corresponding standard errors and $p$-values) are presented in Tables 6 and 7; significant differences were found between the IOSs, as reported at the bottom and left of the tables. Medians and median absolute deviations (from median, MAD) are presented in Table 8 and Fig. 10. Correlations were found between these values: medians of linear and cross distances $(0.80,95 \%$ CI $0.41-0.94, p=0.0019)$, MADs of linear and cross distances $(0.66,95 \%$ CI $0.14-$ $0.90, p=0.019)$, medians and MADs of linear distances $(-0.52,95 \%$ CI $-0.84-0.07, p=0.082)$, and medians and MADs of cross distances $(0.13,95 \%$ CI $-0.48-0.65, p=$ 0.696). Finally, linear and cross distances were evaluated 


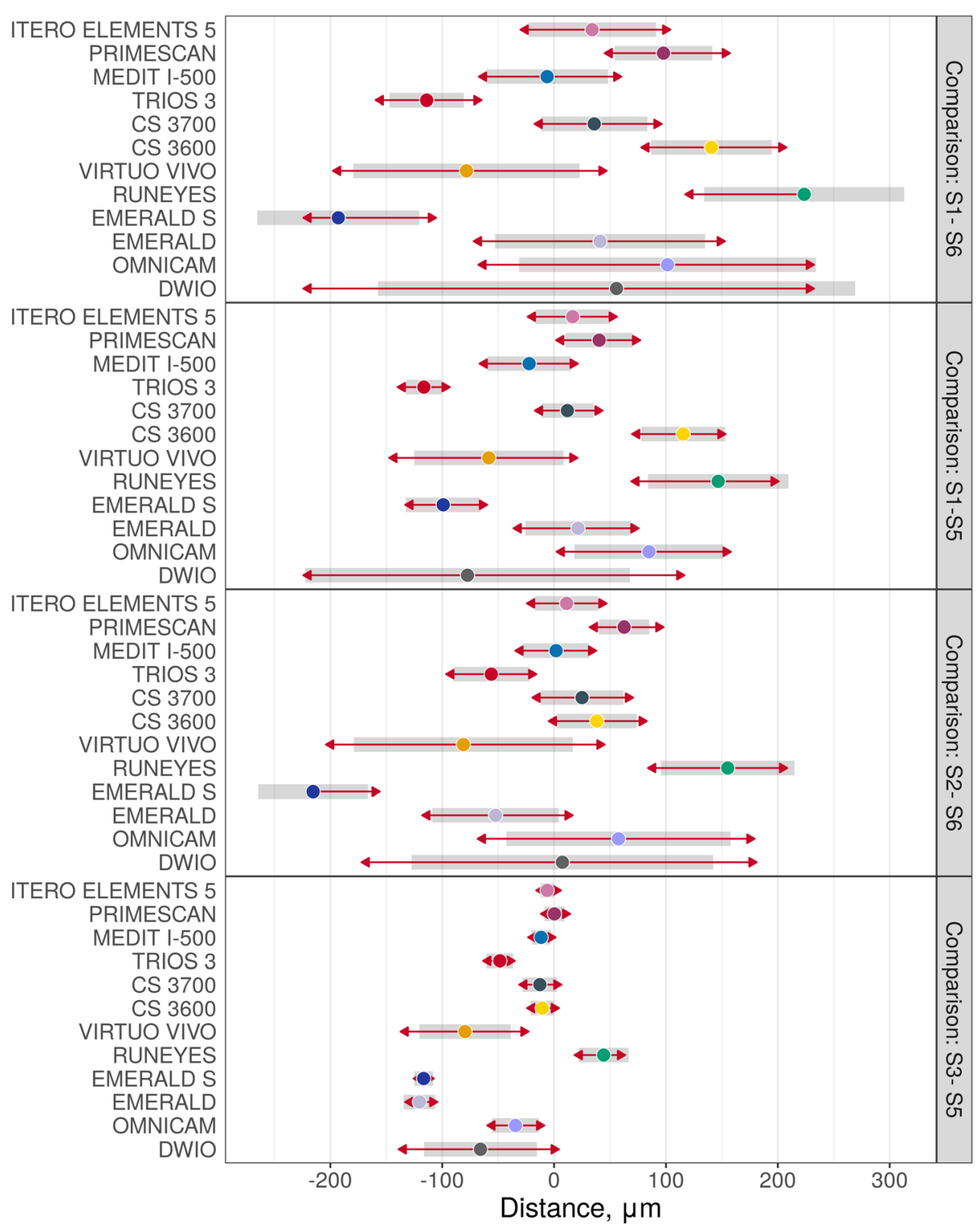

Fig. 12 Cross distances: mean error (Cl 95\%) and comparison between the different intraoral scanners. The overlap of the red arrows between pairs of scanners indicates no statistically significant difference

for each of the SB pairs, as reported in Figs. 11 and 12, respectively. In these figures, the overlap of the red arrows between pairs of scanners indicates no statistically significant difference. Once again, a statistically significant difference was found among different scanner pairs.

\section{Discussion}

To date, few clinical studies have supported the use of optical impression for manufacturing FA restorations in the completely edentulous patient; these studies are limited to the restorations of patients with 4 implants [3032]. In more complex clinical situations, with FA supported by between 6 and 8 implants, the scientific literature has not yet validated the use of optical impression
$[16,17,33]$. For this reason, and since the technological development of IOSs is constant through the improvement and implementation of new software and hardware, constant updates are needed on the accuracy of the scanners on the market.

In recent years, the scientific literature has attempted to investigate the accuracy of IOSs to extend the use of the optical impression to complex clinical applications, such as capturing impressions for modelling and manufacturing FA restorations via a full digital workflow [14, 15, 19-26, 29].

Most studies investigating the trueness of optical impressions that are currently available in the scientific literature have used a mesh/mesh approach, 
superimposing IOS models onto an RM using best-fit algorithms, and these functions align the meshes to assess the minimum error $[14,15,23,24,29]$. As a consequence, the error is distributed homogeneously throughout the whole mesh $[14,15,29]$. This method is valid to assess the overall trueness because it is immediate and not affected by other variables (tolerances in the fabrication of the SBs, for example) [15, 29]. However, in implant-supported restorations, it is also important to assess the error between fixation points; even a single error localised in one point can determine a clinical misfit of the prosthetic structure. Some studies have therefore attempted to assess distance or angulation errors between fixation points $[25,26]$. To make linear measurements that are reliable, however, it is necessary to work on library files (or nurbs files), on which specific landmarks (such as the centroids) can be precisely and automatically identified by the software. Working with nurbs files also allows more faithfully replicating what happens clinically in the early stages of prosthetic CAD [27].

Our present in vitro study therefore used three different methods to investigate the trueness of 12 IOSs in the FA implant impression: a mesh/mesh method and a nurbs/nurbs method to evaluate overall trueness, and the computation of linear and cross distances between the SBs to evaluate local trueness. In our study, statistically significant differences were found between the different IOSs, as previously reported [14, 15, 19-26, 29]. In particular, the mesh/mesh and nurbs/nurbs analysis have allowed identifying three groups of scanners, characterised by different levels of trueness. The first group, comprising the IOSs with the highest accuracy, consisted of ITERO ELEMENTS 5D ${ }^{\circ}$, PRIMESCAN ${ }^{\circ}$, CS $3700^{\circ}$, CS $3600^{\circ}$, TRIOS $3^{\circ}$ and i $-500^{\circ}$. These scanners have an average intrinsic error $<40 \mu \mathrm{m}$ with the mesh/mesh method and $<25 \mu \mathrm{m}$ with the nurbs/nurbs method and represent a theoretically compatible solution for taking impressions for FA restorations. The second group of scanners presented positive results, although probably still not compatible with the capture of a FA impression. These were EMERALD $S^{\circ}$, EMERALD ${ }^{\circ}$, OMNICAM ${ }^{\circ}$, VIRTUO $\mathrm{VIVO}^{\circ}$ and RUNEYES ${ }^{\circ}$, which presented an average intrinsic error between 40 and $80 \mu \mathrm{m}$ with the mesh/mesh method and between 25 and $50 \mu \mathrm{m}$ with the nurbs/ nurbs method. DWIO ${ }^{\circ}$ remained distanced from all the others, with an intrinsic error $>80 \mu \mathrm{m}$ in the mesh/mesh analysis and $>50 \mu \mathrm{m}$ in the nurbs/nurbs analysis, certainly incompatible with the FA impression. The data of the overall trueness were confirmed by the analysis of the local distances between the SBs, i.e. the linear and cross distances, which again highlighted the existence of three groups of IOSs in this study, characterised by different performances. In fact, linear error analysis along the scan revealed higher reliability for ITERO ELEMEN TS 5D ${ }^{\circ}$, PRIMESCAN ${ }^{\circ}$, CS $3700^{\circ}$, CS $3600^{\circ}$, TRIOS3 ${ }^{\circ}$ and $\mathrm{i}-500^{\circ}$, which showed lower errors than other IOSs. For the particular scanning strategy used in this study, it was not possible to evaluate in detail, for each scanner, the percentage growth of the error as the scan proceeded; however, it was evident that greater variability was present in the paths S2-S3 and S4-S5, corresponding to the area of greatest curvature of the physical model. This finding must be confirmed by further studies, but it would seem to indicate difficulty for IOSs in accurately detecting stretches of curvature. The evaluation of cross measurements naturally resulted in larger errors, in direct proportion to the actual distance between the SBs. Here, too, the evaluation showed significant differences between the different IOSs.

The main advantage of this study is in having compared 12 IOSs, and done so using different techniques, to understand the intrinsic trueness of the scanners at a global and local level by measuring the distances between the different SBs. On one hand, the evaluation with the mesh/mesh method has the advantage of directly highlighting the quality of the scan. In this study, with the mesh/mesh analysis, the best absolute performance was obtained by CS $3700^{\circ}$ (mean error $30.4 \mu \mathrm{m}$; 95\% CI $26.7-34.5 \mu \mathrm{m}$ ) followed by ITERO ELEMENTS $5 \mathrm{D}^{\circ}$ (mean error $31.4 \mu \mathrm{m}$; 95\% CI $29.2-33.8 \mu \mathrm{m}$ ) and i $500^{\circ}$ (mean error $32.2 \mu \mathrm{m}$; 95\% CI 28.4-36.6 $\mu \mathrm{m}$ ). These IOSs were the best in the representation of the SBs and the tissues around them, although in an in vitro study, the soft tissues are a resin copy of the real human gums. On the other hand, the nurbs/nurbs evaluation allows replicating what happens clinically, when within the CAD software the meshes of the SBs are replaced with the corresponding library file, generating a hybrid virtual model on which the modelling takes place. This approach specifically assesses the sole trueness of the position of the implants after the mesh/nurbs replacement in CAD, without any interference from the soft tissues; it is also prerequisite for the correct implementation of the analysis of the distances between the SBs, carried out as an evaluation of the distances between the centroids at their bases. In the analysis of the overall trueness with the nurbs/nurbs method, the best results were obtained by ITERO ELEMENTS 5D ${ }^{\circ}$ (mean error $16.1 \mu \mathrm{m} ; 95 \%$ CI $12.9-20.1 \mu \mathrm{m}$ ), followed by PRIMESCA $\mathrm{N}^{\circ}(19.3 \mu \mathrm{m} ; 95 \%$ CI $16.3-22.9 \mu \mathrm{m})$ and TRIOS $3^{\circ}$ (mean error $20.2 \mu \mathrm{m}$; 95\% CI $18.1-22.7 \mu \mathrm{m}$ ). These results reflect a very low error in the position of the SBs with these IOSs, which could certainly be considered compatible, in all cases, with the realisation of a FA restoration via a full digital workflow. The evaluation of the distances between the single SBs confirmed these positive results, particularly with regard to the linear distances 
(distances along the arch). Obviously, as expected, the local errors tended to grow in the cross distances, particularly between the most distal SBs, but this error is certainly contained compared to what was described only a few years ago in similar studies $[25,33]$.

However, the data presented in this study, which refer to the intrinsic trueness of the different IOSs analysed, must be taken with caution. The IOS is not the only factor involved in determining the final accuracy of an optical impression: the operator [34], patient [35], light conditions [36] and SB [37-40] are also key. The operator is essential because different scanning strategies and different levels of experience can determine different results, as reported in the literature [34]. In the present study, all models were captured by the same operator with many years of experience in intraoral scanning; however, the choice of scan strategy may have favoured some IOSs over others. To date, unfortunately, little is known about the effects of different scanning strategies, since the scientific literature on this topic is scarce [2, 34], and even the manufacturers have not clarified this aspect in full. The patient is equally important. Implants can be inserted in different positions, inclinations and depths, and these factors can positively (or negatively) influence the final trueness of the scan [35]. With regard to this aspect, the literature is scarce too $[16,33]$, and investigating more deeply the effects of these variables is advisable. In the present study, the SBs were rather parallel to each other, simulating an ideal condition with implants placed after a guided surgery procedure; this condition can be considered ideal but is not always found in clinical practice. Light conditions are another factor of great importance in intraoral scanning [36]. In the present in vitro study, all scans were captured in the same environment, under controlled light conditions; however, these conditions are very different from those of the oral cavity, and the literature must certainly investigate in more detail how much this can affect the quality of the scans [36]. Finally, the SB plays a fundamental role, being the device for transferring the implant position [37-41]. Manufacturing tolerances [37] can cause errors in the transfer of the implant position in the space. This is particularly true for implants with a conical connection, where a minimal tolerance can have important effects on the vertical position of the fixture in the space (i.e. $\mathrm{z}$-axis) with respect to the library. Assembly errors (in the case of SBs composed of two assembled portions), as well as an incongruous screwing [38], can represent other sources of error. Finally, the shape and material of the SBs are important because they respectively influence the behaviour of the CAD superposition algorithm [27, 39] and the absorption or reflection of light $[39,40]$.
Finally, the present study has some limitations. First, it is an in vitro study. Although scrupulously conducted, and although it is not possible to determine the trueness of an IOS in vivo, an in vitro study cannot exactly reproduce the characteristics present in the patient's mouth (conditions of light, humidity, saliva). The scanning of plaster models is certainly easier than an intraoral scan, which has limits of space. Furthermore, the patient's tissues are radically different from a plaster model and have different optical behaviour when hit by light. This must always be kept in mind, although in the edentulous patient to be rehabilitated with FA, no teeth are present. A further limitation of the present work, as already described, lies in the choice of the scanning technique [14], which could have favoured some scanners over others. The use of a desktop scanner for the capture of the reference model could also be considered a limitation. Although this machine is certified for an accuracy of $5 \mu \mathrm{m}$, and although this approach has been used in many previous studies [14], a CMM or articulated arm can be considered more reliable tools in capturing reference measurements. Only the centroids at the base (and not the centroids at the top of the SBs) were used for the evaluation of linear and cross distances. Finally, the present study could have collected further and interesting data relating to the linear error increase during scan progression, if only the scan strategy had foreseen the departure from a specific sector of the physical model $(x$ example, right posterior sector only). In fact, as previously reported $[5,16,17,25]$ and recently confirmed by Walter Renne and colleagues in an in vitro study on a dentate model [42], the progression of the scan tends to bring with it an increase in percentage linear error. Unfortunately, this evaluation was not possible in the present study, since the operator was free to start from the right or left posterior area of the model indifferently; the data thus collected do not allow an evaluation of the exact percentage growth of the error along the progression of the scan. In this study, all scans were captured in a specific period (January-February 2020) and therefore with the latest version of the acquisition software available for each of the machines at that time. However, the release of new acquisition software is known to be able to significantly improve the accuracy of an IOS; therefore, the results presented in this study are valid for that period and specific acquisition software. Further studies on the same IOSs with the latest acquisition software are thus needed, to better understand the trueness of the different scanners that are now available.

\section{Conclusions}

The present in vitro study investigated the trueness of 12 IOSs in FA implant impression using three different methods: a mesh/mesh method and a nurbs/nurbs 
method for the evaluation of the overall trueness, and measurement of linear and cross distances between SBs for the evaluation of local trueness. Statistically significant differences emerged in accuracy between different IOSs, and some may be more suitable for optical impression for the manufacture of implant-supported longspan restorations such as FAs. The results of the overall trueness assessment were confirmed by the local analysis of the distances between the different SBs. Despite some limitations, this study can provide important information relating to the intrinsic error with different IOSs, and therefore useful indications for choosing the ideal machine for FA impression. However, it is important to remember that other factors are important in determining the reliability of an optical impression, including the operator, patient, environmental conditions and SB. Further studies are therefore necessary to understand the weight of each factor in determining the final error in the optical impression.

\section{Abbreviations}

IOS: Intraoral scanner; 3D: Three-dimensional; STL: Standard tessellation language; CAD/CAM: Computer-aided-design/ computer-assisted manufacturing; SC: Single crown; PP: Partial prosthesis; FA: Full-arch; CMM: Coordinate measuring machine; SB: Scanbodies; CAD: Computer-aided-design; NURBS: Non-uniform rational b-spline; PEEK: Polyether-ether-ketone LED: Light-emitting-diode; SS: Stable scan stage; RM: Reference model; RICP: Robust-iterative-closest-point; PTP: Point-to-plane; SD: Standard deviation; $\mathrm{Cl}$ : Confidence interval

\section{Acknowledgements}

The authors are grateful to Megagen implants, for having provided free of charge to authors the PEEK scanbodies and implant analogs and used in the present study, and to Uli Hauschild, Dental Technician, and Federico Manes, CAD Designer, for having provided the stone cast models used in this study.

\section{Authors' contributions}

All authors made substantial contributions to the present study. In details, FGM contributed to conception and design of the study, acquisition of data (he acquired all data with the 12 different IOSs), analysis and interpretation of data; he was, moreover, involved in writing and editing the manuscript. MB contributed with the acquisition of data. HL and VR critically evaluated all data and made the statistical evaluation. OA and CM revised the manuscript before submission. All authors read and approved the final manuscript.

\section{Funding}

The present in vitro study was not funded, nor supported by any grant. All the scanners and materials used here belonged to the authors, and nothing was provided by third parties or private Companies: therefore, the authors have no conflict of interest related to the present work.

\section{Availability of data and materials}

The. STL files and the 3D surface models obtained in this study with the different 12 IOS as well as the reference files obtained with the desktop scanner belong to the authors, and are therefore available only upon reasonable request, after approval by all the authors.

\section{Ethics approval and consent to participate}

No patient data was used here, and no patients did contribute in any way to the present in vitro study: therefore, no Ethics Committee approval nor consent to participate was requested for this research.

\section{Consent for publication}

Not applicable.

\section{Competing interests}

The authors declare that they have no competing interests in relation to the present study. Francesco Mangano is a Section Editor for BMC Oral Health.

\section{Author details}

${ }^{1}$ Department of Prevention and Communal Dentistry, Sechenov First State Medical University, 119992 Moscow, Russia. ${ }^{2}$ Ars and Technology, Sotto il Monte Giovanni XXIII, 24039 Bergamo, Italy. ${ }^{3}$ Academic Teaching and Research Institution of Johann Wolfgang Goethe University, 60323 Frankfurt am Main, Germany. ${ }^{4}$ Department of Prosthodontics, Institute of Odontology, Faculty of Medicine, Vilnius University, LT-01513 Vilnius, Lithuania.

${ }^{5}$ Department of Dental Sciences, Vita and Salute University San Raffaele, 20132 Milan, Italy.

Received: 5 August 2020 Accepted: 15 September 2020

Published online: 22 September 2020

\section{References}

1. Joda T, Ferrari M, Gallucci GO, Wittneben JG, Brägger U. Digital technology in fixed implant prosthodontics. Periodontol 2000. 2017:73(1):178-92.

2. Mangano F, Gandolfi A, Luongo G, Logozzo S. Intraoral scanners in dentistry: a review of the current literature. BMC Oral Health. 2017;17(1):149.

3. Joda T, Zarone F, Ferrari M. The complete digital workflow in fixed prosthodontics: a systematic review. BMC Oral Health. 2017;17(1):124.

4. Joda T, Ferrari M, Bragger U, Zitzmann NU. Patient reported outcome measures (PROMs) of posterior single-implant crowns using digital workflows: a randomized controlled trial with a three-year follow-up. Clin Oral Implants Res. 2018;29(9):954-61.

5. Papaspyridakos P, Vazouras K, Chen YW, Kotina E, Natto Z, Kang K, Chochlidakis K. Digital vs conventional implant impressions: a systematic review and meta-analysis. J Prosthodont. 2020. https://doi.org/10.1111/jopr. 13211 Online ahead of print.

6. Gallardo YR, Bohner L, Tortamano P, Pigozzo MN, Laganá DC, Sesma N. Patient outcomes and procedure working time for digital versus conventional impressions: a systematic review. J Prosthet Dent. 2018;119(2): 214-9.

7. Mangano F, Veronesi G. Digital versus analog procedures for the prosthetic restoration of single implants: a randomized controlled trial with 1 year of follow-up. Biomed Res Int. 2018;2018:5325032.

8. Joda T, Bragger U, Zitzmann NU. CAD/CAM implant crowns in a digital workflow: five-year follow-up of a prospective clinical trial. Clin Implant Dent Relat Res. 2019;21(1):169-74.

9. Lerner H, Mouhyi J, Admakin O, Mangano F. Artificial intelligence in fixed implant prosthodontics: a retrospective study of 106 implant-supported monolithic zirconia crowns inserted in the posterior jaws of 90 patients. BMC Oral Health. 2020;20(1):80.

10. de Oliveira NRC, Pigozzo MN, Sesma N, Laganá DC. Clinical efficiency and patient preference of digital and conventional workflow for single implant crowns using immediate and regular digital impression: a meta-analysis. Clin Oral Implants Res. 2020;31(8):669-86.

11. Sailer I, Mühlemann S, Fehmer V, Hämmerle CHF, Benic GI. Randomized controlled clinical trial of digital and conventional workflows for the fabrication of zirconia-ceramic fixed partial dentures. Part I: time efficiency of complete-arch digital scans versus conventional impressions. J Prosthet Dent. 2019;121(1):69-75.

12. Mühlemann S, Benic Gl, Fehmer V, Hämmerle CHF, Sailer I. Randomized controlled clinical trial of digital and conventional workflows for the fabrication of zirconia-ceramic posterior fixed partial dentures. Part II: time efficiency of CAD-CAM versus conventional laboratory procedures. J Prosthet Dent. 2019;121(2):252-7.

13. Benic Gl, Sailer I, Zeltner M, Gütermann JN, Özcan M, Mühlemann S. Randomized controlled clinical trial of digital and conventional workflows for the fabrication of zirconia-ceramic fixed partial dentures. Part III: marginal and internal fit. J Prosthet Dent. 2019;121(3):426-31.

14. Mangano FG, Hauschild U, Veronesi G, Imburgia M, Mangano C, Admakin O. Trueness and precision of 5 intraoral scanners in the impressions of single and multiple implants: a comparative in vitro study. BMC Oral Health. 2019; 19(1):101.

15. Di Fiore A, Meneghello R, Graiff L, Savio G, Vigolo P, Monaco C, Stellini E. Full arch digital scanning systems performances for implant-supported fixed 
dental prostheses: a comparative study of 8 intraoral scanners. J Prosthodont Res. 2019;63(4):396-403.

16. Wulfman C, Naveau A, Rignon-Bret C. Digital scanning for complete-arch implant-supported restorations: a systematic review. J Prosthet Dent. 2020; 124(2):161-7.

17. Ahlholm P, Sipilä K, Vallittu P, Jakonen M, Kotiranta U. Digital versus conventional impressions in fixed prosthodontics: a review. J Prosthodont. 2018;27(1):35-41.

18. Albdour EA, Shaheen E, Vranckx M, Mangano FG, Politis C, Jacobs R. A novel in vivo method to evaluate trueness of digital impressions. BMC Oral Health. 2018;18(1):117.

19. Schmidt A, Billig JW, Schlenz MA, Wöstmann B. A new 3D-method to assess the inter implant dimensions in patients - a pilot study. J Clin Exp Dent. 2020;12(2):e187-92.

20. Mandelli F, Zaetta A, Cucchi A, Mangano FG. Solid index impression protocol: a hybrid workflow for high accuracy and passive fit of full-arch implant-supported restorations. Int J Comput Dent. 2020;23(2):161-81.

21. Iturrate $M$, Lizundia $E$, Amezua $X$, Solaberrieta E. A new method to measure the accuracy of intraoral scanners along the complete dental arch: a pilot study. J Adv Prosthodont. 2019;11(6):331-40.

22. Gómez-Polo M, Ballesteros J, Perales-Padilla P, Perales-Pulido P, Gómez-Polo C, Ortega R. Guided implant scanning: a procedure for improving the accuracy of implant-supported complete-arch fixed dental prostheses. J Prosthet Dent. 2020;124(2):135-9.

23. Mangano FG, Veronesi G, Hauschild U, Mijiritsky E, Mangano C. Trueness and precision of four intraoral scanners in Oral Implantology: a comparative in vitro study. PLoS One. 2016;11(9):e0163107.

24. Bilmenoglu C, Cilingir A, Geckili O, Bilhan H, Bilgin T. In vitro comparison of trueness of 10 intraoral scanners for implant-supported complete-arch fixed dental prostheses. J Prosthet Dent. 2020:S0022-3913(19)30754-1. https://doi. org/10.1016/j.prosdent.2019.11.017 Online ahead of print.

25. van der Meer WJ, Andriessen FS, Wismeijer D, Ren Y. Application of intraoral dental scanners in the digital workflow of implantology. PLoS One. 2012;7(8):e43312.

26. Roig E, Garza LC, Álvarez-Maldonado N, Maia P, Costa S, Roig M, Espona J. In vitro comparison of the accuracy of four intraoral scanners and three conventional impression methods for two neighboring implants. PLoS One. 2020;15(2):e0228266

27. Mangano F, Lerner H, Margiani B, Solop I, Latuta N, Admakin O. Congruence between meshes and library files of implant scanbodies: an in vitro study comparing five intraoral scanners. J Clin Med. 2020;9(7):E2174.

28. Jablonski R, Elneklawy M, Osnes C, Ferrari M, Wu J, Keeling A. Guided scanning improves full arch precision of an intra-Oral scanner. Vancouver: IADR/AADR/CADR General Poster Session; 2019. p. 1574.

29. Imburgia M, Logozzo S, Hauschild U, Veronesi G, Mangano C, Mangano FG. Accuracy of four intraoral scanners in oral implantology: a comparative in vitro study. BMC Oral Health. 2017;17(1):92.

30. Ender A, Attin T, Mehl A. In vivo precision of conventional and digital methods of obtaining complete-arch dental impressions. J Prosthet Dent. 2016;15:313-20.

31. Chochlidakis K, Papaspyridakos P, Tsigarida A, Romeo D, Chen YW, Natto Z, Ercoli C. Digital versus conventional full-arch implant impressions: a prospective study on 16 edentulous maxillae. J Prosthodont. 2020;29:281-6.

32. Mangano F, Mangano C, Margiani B, Admakin O. Combining intraoral and face scans for the design and fabrication of computer-assisted design/ computer-assisted manufacturing (CAD/CAM) polyether-ether-ketone (PEEK) implant-supported bars for maxillary overdentures. Scanning. 2019;2019: 4274715.

33. Flügge T, van der Meer WJ, Gonzalez BG, Vach K, Wismeijer D, Wang P. The accuracy of different dental impression techniques for implant-supported dental prostheses: a systematic review and meta-analysis. Clin Oral Implants Res. 2018;29(Suppl. 16):374-92.

34. Latham J, Ludlow M, Mennito A, Kelly A, Evans Z, Renne W. Effect of scan pattern on complete-arch scans with 4 digital scanners. J Prosthet Dent. 2020;123:85-95.

35. Tan MY, Yee SHX, Wong KM, Tan YH, Tan KBC. Comparison of threedimensional accuracy of digital and conventional implant impressions: effect of Interimplant distance in an edentulous arch. Int J Oral Maxillofac Implants. 2019;34:366-80.

36. Revilla-León M, Jiang P, Sadeghpour M, Piedra-Cascón W, Zandinejad A Özcan M, Krishnamurthy VR. Intraoral digital scans-part 1: influence of ambient scanning light conditions on the accuracy (trueness and precision) of different intraoral scanners. J Prosthet Dent. 2019:S0022-3913(18)30992-2. https://doi.org/10.1016/j.prosdent.2019.06.003 Online ahead of print.

37. Schmidt A, Billig JW, Schlenz MA, Rehmann P, Wöstmann B. Influence of the accuracy of intraoral Scanbodies on implant position: differences in manufacturing tolerances. Int J Prosthodont. 2019;32:430-2.

38. Arcuri L, Pozzi A, Lio F, Rompen E, Zechner W, Nardi A. Influence of implant scanbody material, position and operator on the accuracy of digital impression for complete-arch: a randomized in vitro trial. J Prosthodont Res. 2020;64(2):128-36.

39. Mizumoto RM, Yilmaz B. Intraoral scan bodies in implant dentistry: a systematic review. J Prosthet Dent. 2018;120:343-52.

40. Moslemion M, Payaminia L, Jalali H, Alikhasi M. Do type and shape of scan bodies affect accuracy and time of digital implant impressions? Eur J Prosthodont Restor Dent. 2020:28:18-27.

41. Huang R, Liu Y, Huang B, Zhang C, Chen Z, Li Z. Improved scanning accuracy with newly designed scan bodies: an in vitro study comparing digital versus conventional impression techniques for complete-arch implant rehabilitation. Clin Oral Implants Res. 2020;31:625-33.

42. Nagy Z, Simon B, Mennito A, Evans Z, Renne W, Vág J. Comparing the trueness of seven intraoral scanners and a physical impression on dentate human maxilla by a novel method. BMC Oral Health. 2020;20(1):97.

\section{Publisher's Note}

Springer Nature remains neutral with regard to jurisdictional claims in published maps and institutional affiliations.
Ready to submit your research? Choose BMC and benefit from:

- fast, convenient online submission

- thorough peer review by experienced researchers in your field

- rapid publication on acceptance

- support for research data, including large and complex data types

- gold Open Access which fosters wider collaboration and increased citations

- maximum visibility for your research: over $100 \mathrm{M}$ website views per year

At $\mathrm{BMC}$, research is always in progress.

Learn more biomedcentral.com/submissions 